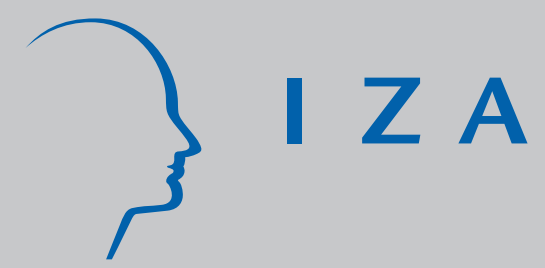

IZA DP No. 8968

The Hidden Cost of Labor Market Entry During Recession: Unemployment Rate at Entry and Occupational Injury Risk of Young Workers

Roberto Leombruni

Tiziano Razzolini

Francesco Serti

April 2015 


\title{
The Hidden Cost of Labor Market Entry During Recession: Unemployment Rate at Entry and Occupational Injury Risk of Young Workers
}

\author{
Roberto Leombruni \\ University of Turin \\ and $L A B O R$ \\ Tiziano Razzolini \\ University of Siena, \\ $I Z A$ and $L A B O R$ \\ Francesco Serti \\ University of Alicante
}

Discussion Paper No. 8968

April 2015

IZA
P.O. Box 7240
53072 Bonn
Germany

Phone: +49-228-3894-0

Fax: +49-228-3894-180

E-mail: iza@iza.org

Any opinions expressed here are those of the author(s) and not those of IZA. Research published in this series may include views on policy, but the institute itself takes no institutional policy positions. The IZA research network is committed to the IZA Guiding Principles of Research Integrity.

The Institute for the Study of Labor (IZA) in Bonn is a local and virtual international research center and a place of communication between science, politics and business. IZA is an independent nonprofit organization supported by Deutsche Post Foundation. The center is associated with the University of Bonn and offers a stimulating research environment through its international network, workshops and conferences, data service, project support, research visits and doctoral program. IZA engages in (i) original and internationally competitive research in all fields of labor economics, (ii) development of policy concepts, and (iii) dissemination of research results and concepts to the interested public.

IZA Discussion Papers often represent preliminary work and are circulated to encourage discussion. Citation of such a paper should account for its provisional character. A revised version may be available directly from the author. 


\title{
ABSTRACT
}

\section{The Hidden Cost of Labor Market Entry During Recession: Unemployment Rate at Entry and Occupational Injury Risk of Young Workers ${ }^{*}$}

\begin{abstract}
A unique dataset from Italy is used to study the effect of unfavorable business cycle conditions at entry on future workplace safety of young workers. We find that higher local unemployment rates at entry have a positive effect both on severe injuries and non-severe injuries. While the impact of unemployment at entry on severe injuries is constant over time, the effect on non-severe injuries is less pronounced and increases with experience, thus indicating that the reporting behavior is affected by initial conditions. In addition, the same cohorts of workers experience slower wage growth, despite being initially compensated for the occupational injury risk. These results suggest that entrants during recession may be persistently locked into low quality jobs and that the mix of hazardous tasks offered by employers throughout the business cycle can be used to overcome wage and other institutional rigidities of the Italian labor market.
\end{abstract}

JEL Classification: J24, J28, J31

Keywords: unemployment at entry, young workers, workplace injury, job amenities

Corresponding author:

Tiziano Razzolini

Dipartimento di Economia e Statistica

Universitá di Siena

Piazza San Francesco 7

53100 Siena

Italy

E-mail: tiziano.razzolini@unisi.it

\footnotetext{
* Financial support from the Spanish Ministry of Education and Science (ECO2012-34928), and from the Compagnia di San Paolo (TO-Call3-20120119-The Popart Network) is gratefully acknowledged. We wish to thank the following individuals and organizations for their helpful comments and suggestions: Giuseppe Bertola, Alberto Dalmazzo, Michele Pellizzari, Climent Quintana Domeque, Jan C. van Ours, Anzelika Zaiceva and the participants at AIEL (2014), EALE (2012) and seminars at University of Alicante, University Federico II of Naples, University of Modena and Reggio Emilia, University of Sheffield, University of Siena, University of Tilburg. We also thank Massimiliano Giraudo and Antonella Bena for the help in identifying injuries requiring immediate care. The usual disclaimer applies.
} 


\section{Introduction}

The macroeconomic conditions faced by workers entering the labor market for the first time may persistently affect their future labor market outcomes and wellbeing. The accumulated evidence mainly focuses on the negative effects of business cycle on future wages and employment prospects of young entrants (Brunner and Kuhn, 2014, Genda et al., 2010, Kahn, 2010, Kwon et al., 2010, Oreopoulos et al., 2012, Oyer, 2006). In contrast, due to data limitations, little attention has been devoted to non-pecuniary job attributes. These amenities represent an equally relevant component of the compensation package and, especially when wages are rigid and regulated by strict institutional rules, might constitute an important channel of adjustment to negative shocks.

This paper studies the impact of unemployment at entry on workplace safety for a sample of young Italian-born low-medium skilled men who started their first employment between 1994 and 2003. We employ a unique dataset for the period 1994-2003 that combines work histories from Italian administrative data (Work Histories Italian Panel, WHIP) with individual work-related injuries from the Italian Workers' Compensation Authority (INAIL). The data contain exact information on the entry date and the timing of each workplace injury thus allowing us to implement both linear regression models and survival analysis.

Our main finding is that negative labor market conditions at entry determine a long run increase in the injury hazard rate by permanently increasing the number of workrelated accidents. Though this lower level of workplace safety is (at least in part) initially compensated by higher entry wages, workers entered during recessions subsequently ex- 
perience slower wage growth whereas the level of injury risk remains persistently higher. This temporal evolution cannot be simply ascribed to a lower accumulation of experience and/or tenure, as we do not find any significant effect of initial conditions on time worked (conditional or unconditional on being employed) and very small negative effects on tenure only in the long run. We also show that our findings are robust to restricting the analyses to severe injuries, which-due to their consequences and immediate care needs- are not subject to reporting bias (Boone and van Ours, 2006, Boone et al., 2011), and to using a measure of the risk imposed by the working environment which is not affected by workers' behavior in the job as dependent variable. Therefore, we argue that our findings provide evidence on the impact of starting conditions on the time spent by new workers in low-quality jobs offering relatively fewer career prospects.

The analysis of job safety thus appears to be particularly helpful in disentangling the effects of unfavorable entry conditions on career prospects of young workers in labor markets, as the Italian one, characterized by downward wage rigidities (Devicienti et al., 2007) in which, especially for young workers (Berton and Garibaldi, 2012), wages are to a large extent determined by collective agreements. Moreover, a typical insider-outsider dualism emerges when wage compression is coupled with employment protection legislation (EPL), where incumbent workers are protected against external shocks and entrants face a reduction in labor market opportunities. Such a dualism can be sustained only if insiders are able to fix entrants' wage in order to avoid any sort of underbidding. Due to the existence of high labor turnover costs and insider retaliation strategies, entrants are very unlikely to be hired on terms that go against insider interest (Bertola, 1999, Lind- 
beck and Snower, 2001). Our findings suggest that, after the wage is set in a standard right-to-manage framework, employers adjust compensations by varying the mix of hazardous task offered to entrants. Through this channel, employers are able to mitigate the disadvantages of wage stickiness and the entry of young workers is more easily accepted by incumbent workers.

To the extent that hazardous tasks are associated with jobs which offer relatively fewer opportunities for skill accumulation or are characterized by a lower transferability of the accumulated skills to higher level occupations, our results may provide evidence supporting human capital models, such as the theory of Gibbons and Waldman (2006), which suggest that if during recessions entrants are assigned to these low-quality tasks, initial conditions may have long-lasting effects. This mechanism may be reinforced by the presence of an insider-outsider divide, as accumulating human capital is also for labor market entrants an investment to become insiders. Therefore, with respect to labor markets characterized by less rigid institutional settings, the incentives of entrants during recessions to search for "better" jobs may be comparatively lower. Indeed, we also find that, different from that observed for other countries, entrants during unfavorable labor market conditions do not display a higher search intensity.

As job safety effects represent a channel through which different types of jobs may affect workers' health conditions, ${ }^{1}$ the results of this paper also complement the studies which relate the (initial) type of occupation to a worker's health status (Case and Deaton, 2005, Fletcher et al., 2011, Sindelar et al., 2007). Finally, analyzing injury dynamics by

\footnotetext{
${ }^{1}$ Injuries might also lead to substantial health costs through an increase in the number of working days lost and a (permanent) reduction of workers' production capacity
} 
their severity reveals that, apart from the contemporaneous economic cycle (Boone and van Ours, 2006, Boone et al., 2011), the starting conditions also affect worker reporting behavior.

The remainder of the present paper is organized as follows. The next section reviews the economic literature on the effect of adverse conditions at entry. Section 3 describes the data. The econometric framework and the empirical results are presented and discussed in Section 4. Section 5 concludes.

\section{Related literature}

Previous literature has mainly investigated the effect of high unemployment at entry on pecuniary labor market outcomes, estimating the degree of persistence of the expected initial adverse impact. Most of the empirical evidence analyzing the effect of unemployment at entry on wages is based on countries characterized by greater wage flexibility than the Italian labor market. The bulk of these studies focus on entrants with at least college education in North America (Genda et al., 2010, Kahn, 2010, Oreopoulos et al., 2012, Oyer, 2006) and detect a wage penalty for those entered during recession which vanishes in about ten years. However, for a sample of Austrian low and medium-skilled workers, Brunner and Kuhn (2014) find a persistent and increasing effect of the initial unemployment rate on wages. Genda et al. (2010) also detect a negative and persistent effect of unemployment at entry on earnings for low and medium-skilled Japanese workers, but not for their US counterparts, and argue that institutional differences (i.e., 
stronger EPL in Japan coupled with a school-based hiring system) may contribute to explaining this result.

Economic theory provides a wide range of possible mechanisms that can explain a persistent effect of initial macroeconomic conditions on labor market outcomes. The quality of the initial job could depend on the economic cycle and affect on-the-job human capital accumulation. According to Gibbons and Waldman (2006), if new entrants facing poor macroeconomic conditions enter the labor market in lower-quality jobs or in tasks which offer relatively fewer opportunities for accumulating skills and for career progress (or are characterized by a lower transferability of the accumulated skills to higher level occupations), initial job or task assignment may have longer term consequences by affecting actual worker productivity. Moreover, including the mere employers' imperfect information about worker productivity could rationalize a persistent effect of initial conditions. According to Oyer (2006), prospective employers could perceive the initial low-rank job as a signal of the workers' ability, without taking into account the macroeconomic conditions at the time of labor market entry. Oreopoulos et al. (2012) show that also a standard job-search model, augmented with mobility costs that increase with job tenure or age, is consistent with persistent effects of unfavorable initial conditions. If the benefits of searching are sufficiently low (or the mobility costs increase sufficiently steeply), the catch-up of unlucky entrants may terminate before the gap is closed. Finally, a persistent effect of macroeconomic conditions at entry is also consistent with the existence of implicit/insurance contracts (e.g. Beaudry and DiNardo, 1991, Harris and Holstrom, 1982). Workers entering the labor market during recessions may tend to accept long-term 
contracts characterized by lower wage growth and job mobility may be costly.

In presence of labor market rigidities, typical of European countries, adverse conditions at entry are likely to affect other outcomes such as employment (see for instance Raaum and Røed, 2006) or other non pecuniary characteristics. The Italian labor market represents an interesting case to study the effect of adverse initial conditions. Among European countries, the Italian labor market ranks the highest position in terms of employment protection legislation (EPL), wage compression and downward wage rigidity as well as centralized wage bargaining and trade union coverage(OECD, 1999, 2004). It is thus reasonable to expect negligible effects of adverse conditions at entry on wages. Indeed, using the same dataset, Leombruni et al. (2013) show that Italian laid-off workers do not experience relevant wage losses, but exhibit a considerable increase in workplace injury risk at reemployment. As in the case of displaced workers, downward wage rigidity is likely to be binding for low skilled labor market entrants and, therefore, it is plausible that employers react to economic downturns by adjusting the mix of hazardous tasks offered to entrants. ${ }^{2}$

\section{Data Description}

We used the WHIP-Salute database, which merges together data on work careers derived from the administrative records of the National Social Security Administration (INPS), with data on work injuries derived from the administrative records of the National Work

\footnotetext{
${ }^{2}$ As emphasized in the literature, the business cycle may influence workers selection into different jobs and tasks. Several studies show that during slowdowns firms allocate incumbent workers to lower skilled tasks (Devereux, 2000, Solon et al., 1997) or lower job levels (Baker et al., 1994)
} 
Injuries Insurance Administration (INAIL) (Bena et al., 2012). The target population includes individuals who worked in the private non-agricultural sector in Italy in the period 1985-2003, from which a $6 \%$ sample has been extracted. Career data provides job start and job end dates, along with the actual duration in weeks of each employment relationship. It also provides information on worker characteristics (age, sex, birthplace, place of work, type of occupation, maternity leave and sick leave), standard labor market outcomes (number of weeks worked in a year and annual earnings) and characteristics of the firms in which individuals are employed (number of employees, sector and firms' opening and closing dates). Weekly wages are computed as the ratio between annual deflated earnings and number of weeks worked in a year, with both variables measured on a full time equivalent scale. The INAIL dataset contains the date of workplace injuries (i.e., accidents that have occurred during a work task), the duration of injury-related leave at the employer-employee level and a description of the type of injury. It includes all injuries leading to a leave of more than three days for the period 1994-2003. ${ }^{3}$ Physicians made all diagnoses and prognoses for workers involved in these accidents. Using the information on the diagnosis we adopt a classification of injuries to identify workplace accidents that require immediate treatment at hospital and for this reason cannot be subject to reporting bias (Boone and van Ours, 2006). These workplace accidents are labeled as immediate care (IC) injuries, whereas the remaining ones are labeled as nonimmediate care injuries (NIC).

We selected Italian-born men who had their first labor market experience between

\footnotetext{
${ }^{3}$ Shorter healing periods do not involve INAIL but are the responsibility of the firm, according to collective contract agreements.
} 
1994 and 2003 and who were under 24 years old at the time of entry. We define "first-time labor market entrants" as those workers who are observed for the first time in the sample in 1994 or later. ${ }^{4}$ We exclude the pre-1971 birth cohorts by considering entrants who are under 24 years old at the time of entry. The resulting sample is representative of $70 \%$ of first time labor market entrants in Italy during 1994-2003. As the WHIP-Salute dataset does not adequately cover the public sector, we also exclude labor market entrants and employment spells in those industries. ${ }^{5}$ Although no information on schooling is available in the data, the restriction on age in practice excludes individuals with higher education/skills (i.e., those with at least a university degree) ${ }^{6}$ and therefore reduces potential unobserved heterogeneity problems related to this important dimension. Moreover, job safety should be less relevant for labor market entrants with higher education, who tend to perform non-manual tasks. Therefore, due both to data limitations and for conceptual reasons, we concentrate on low- to medium-skilled entrants. The restriction on gender is aimed to reduce the unobserved heterogeneity that reflects the complexity of female labor supply behavior over the life cycle.

Following the above-cited literature, we use unemployment rates to proxy for the economic cycle. In particular, we use data on regional Italian unemployment rates for all

\footnotetext{
${ }^{4}$ We can observe the labor market history of individuals since 1985 to 2003.

${ }^{5}$ The following ATECO 1991/ISIC rev 1.1 codes are left out of the analysis: L, M, N, O. This hardly affects the representativeness of the data. Indeed, only $4.9 \%$ of the selected labor market entrants begin their career in the public sector and only $4.7 \%$ of individuals in the final sample have some job spells in the public sector. Finally, because of its high degree of seasonality and undeclared work, we checked that our results are robust to excluding employment spells in the construction sector.

${ }^{6}$ According to the AlmaLaurea surveys (www.almalaurea.it/en/), in 2003 , only $0.7 \%$ of students who completed their undergraduate studies were 23 y.o. or younger, with 28 being the average age of graduation. During the previous years included in our sample the average age of graduation was even higher.
} 
workers over the period 1985-2003 from the Italian National Institute of Statistics (ISTAT). Figure 1 depicts the national and regional unemployment rates over the 1994-2003 period. The slowdown of the Italian economy after 1993 resulted in an increasing trend in unemployment until 1998. A recovery occurred thereafter. Italian regions markedly differ in the level of unemployment, with the South lagging behind the developed North. However, in order to take into account the unobserved heterogeneity connected to the different entry cohorts and the different regional labor markets, our identification strategy is conditional on the region of entry and on the year of entry. Figure 2 demonstrates that after washing out the national trend and the time-constant regional heterogeneity, significant cyclical differences across regions persist: this source of variation is used to identify the effects of local business cycle fluctuations.

Table 1 includes some descriptive statistics for our sample of workers by year of entry. The mean age at entry exhibits a slight increasing trend. The percentage of new entrant manufacturing jobs follows a negative trend which is accompanied by a stable increase of the proportion of entrants in the service sector. The share of workers starting their careers as apprentices and blue collar workers is quite stable at around $88 \%$. However, the categorization of blue versus white collars is likely to conceal a significant amount of heterogeneity in terms of task assignment. The proportion of entrants born in the North of Italy exhibits a negative trend, whereas the percentage of workers born in the South and in the islands increases over time. However, more jobs for new entrants are created in the North, consistent with the historical economic duality between the richer North and the less developed Southern part of the country. It is also interesting to note that 
the proportion of entrants in the Northern regions is higher during the years of increasing unemployment and decreases during the post-1998 recovery period when the proportion of jobs created in the Southern regions increases. Moreover, the difference between the proportion of entrants in the Southern/(Northern) labor markets and the proportion of entrants born in the South/(North) is always negative/(positive). This evidence points to the relevance of mobility from the disadvantaged Southern regions toward the richer Northern part of the country. Table 1 also describes the means of the main labor outcomes analyzed in the paper. The number of injuries has been divided by the number of full time equivalent paid weeks in order to take into account the exposure to risk. We report these variables as the number of injuries per thousand of days worked to improve the readability of the estimates (i.e., to reduce the number of decimals) . Interestingly, there is a clear increase of both IC and NIC injuries in those years characterized by higher unemployment rates. Figure A1 plots the log mean wage by year of experience for cohorts of workers entered in different years. Entry wages seem to follow the same dynamics of injuries, as they are positively correlated with unemployment rates. ${ }^{7}$ However, at closer inspection workers entered during the last years of recession (i.e., 1997-99) seem to experience slower wage growth rates than the other cohorts even though they started at the highest levels of entry wage.

\footnotetext{
${ }^{7} \mathrm{~A}$ similar trend in entry wage is also evident in Figure A3 for a comparable sample of workers selected from the European Consumption Household Panel (ECHP) in the 1994-2000 period.
} 


\section{Estimation Strategy and Effects of Recession at}

\section{Entry}

\subsection{Estimation Strategy}

We study the effect of initial unemployment rate in the region of entry, $u r_{i t}$, on various labor market outcomes over time, $y_{i t}$, by adopting the following specification

$$
y_{i t}=\alpha+\left(\sum_{s=0}^{S} \beta_{s} \mathbf{1}\left[\operatorname{Exp}_{i t}=s\right] u r_{i 0}\right)+\phi u r_{i t}+\psi_{s}+\mu_{b}+\lambda_{r}+\gamma_{l}+\theta_{t}+u_{i t}
$$

Along with introducing unrestricted fixed effects for year of potential experience, $\psi_{s}$, we interact unemployment at entry in region $r$ with dummies specific for each year of potential experience. The effect of the unemployment at entry is thus allowed to be different at each year of potential experience: $\beta_{s}$ represents the marginal effect of the initial unemployment rate s years after entry. In order to isolate the effect of initial labor market conditions from subsequent macroeconomic shocks possibly correlated to initial conditions, we control for the current regional employment rate, $u r_{i t}$. We take into account permanent unobserved heterogeneity connected to the region of birth $\left(\mu_{b}\right)$, to the region of entry $\left(\lambda_{r}\right)$ and to the year of entry cohort $\left(\gamma_{l}\right)$. Finally, $\theta_{t}$ represents a calendar year effect.

We interpret the estimated $\psi_{s}$ as driven by variations in labor demand conditions. In the same way as Oreopoulos et al. (2012), our identification strategy is based on 
the assumption that (conditional on region of birth, region of entry, cohort, experience and calendar year effects) region-cohort specific variations in unemployment rates for all workers are not correlated to shocks at the labor supply of young workers. We implement various robustness checks to make sure that our results are not driven by endogenous labor market entry over the business cycle, both from the perspective of the timing of entry and sorting into different local labor markets. Finally, we repeat the analysis within a duration framework in order to fully exploit all the available information about the timing of the occurrence of injuries.

\subsection{Main Results}

We first focus our analysis on standard labor outcomes such as log weekly wages, log annual earnings and log annual weeks worked. We also use all observations in the period 1994-2003 to construct an index to measure the log mean wage in occupations in the same sector. By observing the effect of $u r_{0}$ on this index we can detect the effect of $u r_{0}$ on the movement of workers in occupations that receive higher or lower salaries on average. ${ }^{8}$ Figure 3 shows the effect of $u r_{0}$ by year of experience on log weekly wages, the log wage index, log annual earnings and the log of weeks worked. The detailed estimation results are reported in Table A1 in the Appendix. Panel (a) indicates that a one point increase in the unemployment rate is associated with an increase in starting wage levels by $1.6 \%$. However, entrants during periods of high unemployment display lower wage growth than workers entered with more favorable labor market conditions. Indeed, the initial premium

\footnotetext{
${ }^{8}$ Mansour (2009) adopts a similar approach but focuses on average wage of the initial occupation.
} 
decreases rapidly and fades away after 7 years of experience. Results in Panel (b) indicate that workers entered during recessions are more likely to start in occupations that receive higher compensations on average. This effect of $u r_{0}$ is more persistent than the effect on the individual wages, thus suggesting that these cohorts of workers may have lower mobility rates out of these occupations. Panels (c) and (d) confirm the presence of a marginal premium also in terms of annual earnings and number of weeks worked, which become insignificant after 6 and 4 years of experience, respectively. As shown in Table A1 in the Appendix, current unemployment rate has a small and negative effect on wages and earnings, but not on annual weeks worked.

Figure 4 displays the pattern of the estimated effect of initial unemployment rate on our proxies of job safety by year of potential experience. Panels (a), (b) and (c) in Figure 4 indicate a positive and significant effect of $u r_{0}$ on the number injuries (per thousand of days worked), which increases over time for all injuries and NIC injuries but remains constant for IC injuries. The detailed estimation results are reported in Table A2. Compared to the average number of injuries observed in the sample, ${ }^{9}$ the estimated effect of one point increase in $u r_{0}$ on the number of all injuries ranges from $3.5 \%$, during the first year of work, to $7.5 \%$, when workers have potentially accumulated ten years of experience. When we restrict the analysis to NIC injuries, the estimated percentage effects are lower, but their temporal pattern increases more steeply (from $2.2 \%$ to $6.4 \%$ ). The estimated percentage losses in terms of IC injuries are instead constant in time but of a greater magnitude (approximately 15\%). The different magnitude and temporal pattern for IC

\footnotetext{
${ }^{9}$ The average number of injuries per thousand of days worked is 0.322 . Distinguishing between NIC and IC injuries, this figure is 0.296 and 0.026 , respectively.
} 
and NIC injuries may be consistent with a reporting behavior similar to that pointed out by Boone and van Ours (2006), Boone et al. (2011): workers beginning their career in a relatively less/more favorable macroeconomic scenario may have a worse/better bargaining position within the firm and may tend to under/over report less serious injuries. This difference in reporting behavior may decrease as workers accumulate experience and their bargaining positions equalize. The fact that such reporting mechanism is absent for IC injuries could explain why we find greater percentage losses in terms of this kind of injuries. It is also worth noting that, consistently with the original Boone and van Ours (2006), Boone et al. (2011) argument, the effect of current unemployment rate reported in Table A2 is negative and significant for all injuries and NIC injuries (columns 1 and 5 ) but it is not statistically significant for IC injuries (column 3): the current economic cycle only affects less serious injuries by changing the incentives to report this kind of injuries. Therefore, we are inclined to think that the effect of the current unemployment rate on injuries mainly reflects the reporting behavior of workers, while the effect of $u r_{0}$, being robust to restricting the analysis to IC injuries, truly implies a lower level of job safety.

\subsection{A different measure of the risk imposed by the work envi- ronment}

In the previous paragraph, by differentiating between IC and NIC injuries, we have shown that our results on job safety are robust to taking into account the reporting behavior of entrants. However, the persistent effect on injuries estimated at the individual level 
might be determined by factors other than the risk imposed by the work environment but that are otherwise connected to starting macroeconomic conditions. Indeed, a higher unemployment rate at entry may act as a "discipline device" (Shapiro and Stiglitz, 1984) inducing workers to exert greater effort and/or it might constitute a stress factor leading to a less cautious behavior. Ideally, a measure of the risk imposed by the working environment may be constructed by using the number of workplace injuries incurred by the colleagues of young entrant " $\mathrm{i}$ " in each firm, but this strategy is not feasible because the WHIP dataset does not contain information on all workers employed at a single firm. Therefore, at a level of greater aggregation, three injury indexes have been computed (i.e., one for each category of injuries: all, IC and NIC) as the sum of injuries in the 1994-2003 divided the corresponding sum of weeks worked in cells defined using occupation (blue versus white collar), sector (ATECO 1991/ISIC rev 1.1 at two digits) and region. These injury incidence rates have been computed using workers over 33 years old to obtain a measure of risk totally independent of the behavior on the job of young entrants. ${ }^{10}$ The value of the indexes calculated for older workers is then imputed to entrants belonging to the same cell. We then use these three injury incidence rates as dependent variables to determine the effect of $u r_{0}$ on the occupation-specific risks faced by workers along their careers. Panels (d), (e) and (f) in Figure 4 describe the estimated effect of $u r_{0}$ on these indexes by year of experience. The results are qualitatively similar to those obtained by using individual level data: entrants in recession persistently lose in terms of job safety.

\footnotetext{
${ }^{10}$ We obtain the same results if we construct the index using all workers or only young workers
} 
Comparing the estimated effects to the observed averages of the indexes, ${ }^{11}$ the estimated effect of one point increase in $u r_{0}$ on the three injury incidence rates is very similar, ranging from $1 \%$ to $2 \%$. The lower magnitude of the estimated percentage effects with respect to what we obtain by using individual level injuries could be explained by the aggregate nature of these indexes which average across the different tasks included in a cell. Finally, the fact that we do not find relevant differences between IC and NIC indexes is probably also due to the aggregate nature of these proxies, which average across workers and therefore eliminate differences in reporting behavior related to initial macroeconomic conditions.

\subsection{Survival Analysis}

In this subsection the information on the exact starting day of each job spell and the exact day of an injury is used to estimate duration models. This methodology allows us to construct a precise measure of risk exposure, to analyze the evolution of injury hazard rates and, by using frailty models, to take into account the role of unobserved heterogeneity among different cohorts of entrants. To incorporate current unemployment rate as a time-varying covariates, employment spells have been split in year-specific records. In our survival analysis, the dataset and log likelihood function are set to account for interval truncations (Cleves et al., 2010), that is periods in which some workers are not observed because they are not employed in the sectors under analysis. ${ }^{12}$ The comparison

\footnotetext{
${ }^{11}$ The average value of the index for all injuries is 10.996. Distinguishing between NIC and IC injuries, this figure is 9.958 and 1.038, respectively.

${ }^{12}$ See Table A4 for details. In a robustness check we have assumed that the exposure to risk is zero during periods of non employment. The time elapsed in non-employment status is thus ignored and all
} 
of the values of the Akaike Information Criterion (AIC) selects the log-logistic regression model as the best parametric model.

The log-logistic regression model in the accelerated failure time (AFT) metric has the following parametrization

$$
\varepsilon_{j}=\exp \left(-x_{j} \beta\right) t_{j}
$$

where $t_{j}$ is failure time and $\varepsilon_{j}$ is distributed as a log-logistic. In this specification a negative coefficient $\beta$ accelerates failure time, that is, injuries occur earlier. We use the same regressors of the linear specifications with the exception of experience and current year dummies. The latter, in presence of year of entry dummies, would implicitly capture time since entry.

In this specification we introduce frailties following a gamma distribution to control for unobserved heterogeneity shared by workers entering in the same year. We thus deal with unobserved heterogeneity adopting a random effect approach instead of the fixed cohort of entry effect used in linear models. In this specification year of entry dummies are used to define shared frailties and are not included as regressors.

Table 2 displays the estimated coefficients from the log-logistic regressions and the hazard ratios from the Cox proportional hazards models for all, NIC and IC injuries respectively. Columns 1, 4 and 7 show the estimates from the baseline log-logistic specification using the following explanatory variables: initial and current unemployment rates, region of entry and region of birth. For all and NIC injuries (columns 1 and 4) the exponentiated coefficients of $u r_{0}$ (i.e. $\exp (-0.046)$ ) imply that a one percentage point employment spells are considered as contiguous. The main results are qualitatively similar. 
increase in initial unemployment rate decreases the time up to the first injury by a factor approximately equal to 0.96 . The exponentiated coefficient of unemployment at entry for IC injuries in Column 7 (i.e. $\exp (-0.089)$ ) indicates a greater reduction in survival time, by a factor equal to 0.91. The specifications including shared frailties in Columns 3, 6 and 9 yield larger coefficients for $u r_{0}$ than the ones estimated in the baseline specification. These coefficients imply that a percentage point increase in $u r_{0}$ reduces survival time by a factor of 0.87 and 0.86 for all (and NIC) injuries and for IC injuries, respectively. Although the (log of) theta coefficients and the likelihood ratio tests show that shared frailties are significantly different from zero, the AIC indicates that the baseline specifications, using year of entry dummies simply as regressors, are to be preferred.

Results from the Cox proportional hazard model in Columns 3, 6 and 9 indicate a similar story. A percentage point increase in the unemployment at entry increases the hazard rate of all injuries and NIC injuries by $2 \%$ (Columns 3 and 6 ). ${ }^{13}$ The coefficient of $u r_{0}$ in Column 9 shows that a percentage point increase in initial unemployment rates implies a $7.3 \%$ reduction in the hazard rate of IC injuries. Interestingly for all injuries and NIC injuries, the use of Cox proportional hazard models, although providing qualitatively the same effect as the log-logistic regression, is rejected by the data. Tests based on Schoenfeld residuals indicate a violation of the proportionality assumption. In particular, the variable-by-variable tests reveal that the Schoenfeld residuals for the initial unemployment rate, as well as year of entry dummies, vary with time. Conversely the proportionality assumption holds for immediate care injuries indicating that unemploy-

\footnotetext{
${ }^{13}$ Figure A2 in the Appendix plots the hazard rates for all injuries estimated by using the baseline log-logistic regression and the Cox Proportional hazard model at $u r_{0}=8$ and $u r_{0}=10$
} 
ment at entry induces a permanent shift in the hazard function. It is worth noting again that current unemployment rate has a much smaller effect for IC than for NIC injuries.

\subsection{Entry over the business cycle}

The literature on wages suggests the potential endogeneity of labor market entry over the business cycle, both from the perspective of the timing of entry and of sorting into different local labor markets.

Potential entrants facing negative macroeconomic conditions could decide to wait for better opportunities, either by accumulating additional years of education or staying out of the labor force, or could be forced to anticipate the entry into the labor market if staying in education becomes economically unviable. Although the education level of entrants is not reported in the WHIP database, we can observe the age at entry, which will be increasing in education and will also reflect delayed entry due to unemployment (which is very high in the Italian context, especially in the South) or non-employment. The results of regressing the age of entry on the regional unemployment rate, region and time dummies is reported in the first column of Table 3 . We estimate that one percentage point increase in the unemployment rate is associated with a tiny rise (of about 0.04) in the average age of entry, which suggests that cohorts entering the labor market during unfavorable conditions tend to be only marginally older. Although small, the effect of the unemployment rate on the age at entry may be the results of strategic educational choices. Actually, high unemployment may exert two opposite effects on the decision to stay in education: a higher unemployment probability reduces the opportunity cost 
of the educational investment, but at the same time reduces the returns to education. Assessing what is the balance between the two effects is therefore an empirical matter. The evidence is scant for Italy. Di Pietro (2006) found a negative relationship between regional unemployment rates and university dropout rates. However, this is on a different outcome and for a period (1987-1998) which only partially overlaps with our study and includes the worst recession (1992-1993) experienced in Italy before the current one. Closer to our study are the results of Carmeci and Chies (2006), who focus on the decision of further education at the end of compulsory education for the period 1993-1999. They find that the level of unemployment rates do influence negatively the decision to invest in further education, but the annual variation in unemployment has a negligible effect. Exploiting pooled data from the Italian Labour Force Survey, we tested the correlation between unemployment and educational choices for our specific sample and time frame. In the second and third column of Table 3, we report the results of logistic regressions in which the probability of being a high school and university student is modeled as a function of the regional unemployment rate, also conditioning on age, region and year dummies. Closer to Carmeci and Chies (2006) results, neither the probability of attending high school nor that of being a university student is found to be affected by the current economic cycle. This suggests that the slightly higher age of entrants detected during economic contractions should be imputed to episodes of unemployment/non-employment before entry rather than to further accumulation of human capital. ${ }^{14}$

Mobility of entrants across regional labor markets could be endogenous with respect to

\footnotetext{
${ }^{14}$ Adding age at entry dummies to the specification (1) leaves the results unaltered. Results are available upon request.
} 
the local business cycle. As shown in Table 4, this threat to identification is more relevant for entrants born in the South of Italy, where $27 \%$ of entrants start working in a region different from the region of birth. The message of these descriptive statistics is confirmed by using a logistic regression to model a dichotomous variable for entering the labor market in a region different from the region of birth as a function of the unemployment rate of the region of birth in the year of entry and year dummies. Indeed, as shown in the fourth column of Table 3, for a one point increase in the unemployment rate in the region of birth, the odds of entering in a region different from the region of birth increases approximately by a factor of 1.11. However, as shown in the fifth column of Table 3, once we introduce region of birth dummies, the economic cycle in the region of birth loses both statistical and economic significance. These results suggest that in our sample immigration decisions are related to permanent differences in job opportunities between regions, but they are not determined by the regional business cycle. Nevertheless, we also replicated the baseline analyses to check the robustness of our results, by: 1) excluding entrants in regions different from the region of birth (see Table A5 in the Appendix); 2) using all the possible interactions between the region of entry dummies and the region of birth dummies as controls (see Table A6 in the Appendix); 3) running regressions separately for entrants born in the North-Center regions and for those born in the South of Italy (see Tables A7 and A8 in the Appendix, respectively). All these robustness checks confirm the basic findings obtained in the baseline regressions. ${ }^{15}$

\footnotetext{
${ }^{15}$ We have also tried to instrument the initial unemployment rate with the unemployment rate at the end of compulsory schooling (14 y.o.) in the place of birth. The results, which are available upon request, are qualitatively similar. However, as argued by Brunner and Kuhn (2014), it is very unlikely that this kind of instrument does not have a direct effect on our dependent variables. Indeed, we have found evidence that, after controlling for the entry unemployment rate, unemployment rate at the end
} 


\subsection{Discussion}

This section concentrates on the characteristics of jobs and firms observed along the careers of young entrants in order to investigate the mechanisms behind the persistent reduction in workplace safety and the lower wage growth estimated for entrants during unfavorable macroeconomic conditions.

The relationship between initial labor market conditions and the type of occupations and firms is analyzed using the same specification of equation (1). Estimates in Table 5 indicate that entrants during recession have a constantly higher probability of working in a blue collar occupation (Column 1) and a lower probability of working in the more sheltered apprentice position (Column 2). Moreover, unfavorable starting conditions negatively affects the probability of being a white collar, but only in the medium-long run (Column 3). The estimates reported in the last two columns of Table 5 indicate that there are no differences driven by initial conditions in firms' characteristics (age and size).

When we introduce initial firm attributes (sector, firm size, firm age) and type of occupation as additional controls in the main regressions, the estimated effects of the initial unemployment rate on labor market outcomes are not affected (see Table A9 in the Appendix). Moreover, results are not even altered by the inclusion of initial firm's employees growth in previous years (not shown), thus suggesting that the cyclical variation in the job-quality is not driven by different kinds of firms recruiting in different stages of the cycle. Similarly, changes in standard contractual arrangements seem not to explain cyclical variation in the job-quality. Indeed, the introduction of initial contractual of compulsory schooling increases the age of entry, and therefore it seems to have also a direct effect on entrants' outcomes. 
code dummies as additional controls does not either affect the main results (not shown), thus confirming that formal contractual arrangements hide a considerable heterogeneity in job quality which, without the injury data, would not have been detected.

Though the nature of the data does not allow us to use firms' fixed effects to control for employers' unobserved heterogeneity, ${ }^{16}$ the above evidence tends to exclude an explanation based on compositional effects based on firm selection. We have further investigated the impact of unemployment at entry on the entire wage distribution to detect possible effects due to selection based on firms' or workers' unobserved characteristics. Figure 5 displays the effect of $u r_{0}$ on the percentiles of the log wage distribution in the year of entry and in the third, sixth and ninth years of experience. The black lines represent the estimated effects using only the regressors of the baseline specification and show that the initial wage premium is distributed along the entire distribution. A similar pattern is followed by the red lines that plot the estimated effect of $u r_{0}$ when the regression includes additional controls for initial firm attributes (sector, average number of employees, age) and type of occupation. These results suggest that, even controlling for the characteristics of the first job and firm, the effects of $u r_{0}$ are not concentrated in specific parts of the distribution and therefore they are probably not driven by the increased or decreased participation of selected groups of workers and/or employers.

Workers' mobility may help explain what drives the increase in injuries and whether such dynamics are consistent with existing theoretical models. By investigating the effect

\footnotetext{
${ }^{16} \mathrm{~A}$ large share of the observations would drop out of the analysis as many firms are observed only in association to the same worker. Also remember that we cannot use workers' fixed effects because our main regressor, the initial unemployment rate, is time invariant.
} 
of initial unemployment rate on workers' mobility we can verify whether entrants during recessions search more intensively (consistent with job-search models), accumulate lower experience or tenure. Table 6 uses the data from the second year of potential experience onward $^{17}$ and the same specification of equation (1) to study how the initial conditions affects the probability of being in a firm different from the entry firm (Column 1), the probability of being in a firm different from that of the previous year (Column 2), firm tenure (Column 3) and the probability of being non-employed. ${ }^{18}$ In sharp contrast with the evidence for less rigid labor markets where between firm mobility is a key ingredient for the catch-up process especially in the short-medium run (see for example Oreopoulos et al., 2012), entrants during recession do not exhibit an higher probability to leave the initial firm and are marginally more mobile only in the long run (see columns 1 and 2). Indeed estimates in column 3 display a very tiny negative effects on tenure (lower for entrants in recessions) only in the long run. Column 4 shows that entrants during recession have a lower probability to be non-employed. This higher attachment to the labor market, coupled with the estimated initial wage premium, ${ }^{19}$ goes against an explanation of the losses based on the lower productivity of workers entering during recession.

Given that we do not detect lower accumulation of tenure or experience for entrants during recessions, our findings could at least in part be rationalized with the human capi-

\footnotetext{
${ }^{17}$ During the year of entry the analyzed outcomes are the same for all workers.

${ }^{18}$ Given the nature of the data, the non-employment status may hide a transition to open ended jobs in the public administration, which is not covered by INPS administrative archives (while temporary work is observed). However, for a young blue collar male, the probability of directly entering as a permanent worker in Italian Public Administration is negligible in those years.

${ }^{19}$ Lower unobserved skills of workers selected in risky jobs has constituted a major obstacle in the estimation of positive wage premium for risk.
} 
tal mechanism proposed by Gibbons and Waldman (2006) which suggests that if entrants are assigned to low-quality tasks during recessions, initial conditions may have persistent effects by decreasing workers productivity. Moreover, as suggested by Oreopoulos et al. (2012), the recovery from unfavorable initial conditions may be hampered by the accumulation of specific human capital, which increases the opportunity cost to change job. In the Italian context these mechanisms may be reinforced, because for labor market entrants accumulating specific human capital may also constitute an investment to become insiders. This could explain why, unlike what is observed for other countries, entrants during unfavorable labor market conditions do not display a higher search intensity and do not catch-up as time passes by. With respect to labor markets characterized by less rigid institutional settings, their incentives to search for "better" jobs may be comparatively lower. This interpretation is also supported by the results of Table A10, where the effects of experience and of the initial conditions are allowed to vary for employees working in a firm different from the entry firm. ${ }^{20}$ We find that movers have lower wage growth and a lower decrease of injuries with experience. The worst evolution of movers' careers could be at least in part explained by lay-offs of less productive workers. Nevertheless, further considering that the estimated effect of initial labor market conditions is the same for movers and for stayers (see Figure A4), our findings indicate that on average changes of employer are not associated to better labor market outcomes neither for workers starting with unfavorable conditions. To account for these patterns alone, job-search models and human capital models should feature prohibitive mobility costs

\footnotetext{
${ }^{20} \mathrm{We}$ add the interactions of these variables with an indicator variable for working in a firm different from the initial firm.
} 
and/or no benefits associated with job search.

\section{Conclusions}

This paper provides evidence on the effect of unemployment at entry on the subsequent injury hazard rates of male workers who entered the Italian labor market in 1994-2003. We interpret the permanent worsening in workplace safety and the temporary wage premium as indicative of more time spent by these cohorts in low quality jobs.

The presence of labor market rigidities and the insider-outsider dualism can amplify the negative effect of unfavorable entry conditions on the allocation and persistence of young workers in low quality jobs. The observed pattern in the reporting of less severe injuries seem to confirm that entrants may be willing to pay a price to enter during recession and may consider it as an investment to become a future insider. Such an investment, may imply a prolonged accumulation of low quality task-specific human capital (Gibbons and Waldman, 2006) which may harm worker productivity.

Our paper conveys an important message for rigid labor markets. A centralized wage setting system can certainly reduce differences in monetary remunerations among different cohorts of workers. However, it cannot prevent adjustments in other job characteristics, especially if the latter amenities are not easily measured and are less subject to bargaining and monitoring. Employers may thus overcome labor market rigidities by varying the composition and the quality of the jobs offered. This change in the mix of hazardous task may represent an important mechanism to enhance flexibility at entry in the labor 
market.

Our findings thus claim that the entire set of job characteristics should be considered by policy-makers when evaluating the effect of macroeconomic shocks. More attention should also be devoted to institutional rigidities which may considerably affect the dimensions along which recessions reduce job quality and create long-lasting disparities among cohorts of workers.

\section{References}

George Baker, Michael Gibbs, and Bengt Holmstrom. The wage policy of a firm. The Quarterly Journal of Economics, 109(4):921-55, November 1994.

Paul Beaudry and John DiNardo. The effect of implicit contracts on the movement of wages over the business cycle: Evidence from micro data. Journal of Political Economy, 99(4):665-88, August 1991.

Antonella Bena, Massimiliano Giraudo, Roberto Leombruni, and Giuseppe Costa. A new italian surveillance system for occupational injuries: characteristics and initial results. American Journal of Industrial Medicine, 55(7):584-592, 2012.

Giuseppe Bertola. Microeconomic perspectives on aggregate labor markets. Handbook of labor economics, 3:2985-3028, 1999.

Fabio Berton and Pietro Garibaldi. Workers and firms sorting into temporary jobs*. The Economic Journal, 122(562):F125-F154, 2012. 
Jan Boone and Jan C. van Ours. Are recessions good for workplace safety? Journal of Health Economics, 25(6):1069-1093, November 2006.

Jan Boone, Jan C. van Ours, Jean-Philippe Wuellrich, and Josef Zweimuller. Recessions are bad for workplace safety. Journal of Health Economics, 30(4):764-773, July 2011.

Beatrice Brunner and Andreas Kuhn. The impact of labor market entry conditions on initial job assignment and wages. Journal of Population Economics, 27(3):705-738, 2014 .

Gaetano Carmeci and Laura Chies. Education and local labour market: The case of italy. Working Papers DiSES 86, Department of Economics and Statistics, University of Trieste, 2006.

Anne Case and Angus S Deaton. Broken down by work and sex: How our health declines. In Analyses in the Economics of Aging, pages 185-212. University of Chicago Press, 2005.

Mario Cleves, William W. Gould, Roberto G. Gutierrez, and Yulia Marchenko. An Introduction to Survival Analysis Using Stata. Number saus3 in Stata Press books. StataCorp LP, January 2010.

Paul J Devereux. Task assignment over the business cycle. Journal of Labor Economics, 18(1):98-124, January 2000.

Francesco Devicienti, Agata Maida, and Paolo Sestito. Downward wage rigidity in italy: 
Micro-based measures and implications*. The Economic Journal, 117(524):F530-F552, 2007.

Giorgio Di Pietro. Regional labour market conditions and university dropout rates: Evidence from italy. Regional Studies, 40(6):617-630, 2006.

Jason M. Fletcher, Jody L. Sindelar, and Shintaro Yamaguchi. Cumulative effects of job characteristics on health. Health Economics, 20(5):553-570, May 2011.

Yuji Genda, Ayako Kondo, and Souichi Ohta. Long-term effects of a recession at labor market entry in japan and the united states. Journal of Human Resources, 45(1): 157-196, 2010.

Robert Gibbons and Michael Waldman. Enriching a theory of wage and promotion dynamics inside firms. Journal of Labor Economics, 24(1):59-108, January 2006.

Milton Harris and Bengt Holstrom. A theory of wage dynamics. Review of Economic Studies, 49(3):315-33, July 1982.

Lisa B. Kahn. The long-term labor market consequences of graduating from college in a bad economy. Labour Economics, 17(2):303-316, April 2010.

Illoong Kwon, Eva Meyersson Milgrom, and Seiwoon Hwang. Cohort effects in promotions and wages: Evidence from sweden and the united states. Journal of Human Resources, $45(3), 2010$.

Roberto Leombruni, Tiziano Razzolini, and Francesco Serti. The pecuniary and non- 
pecuniary costs of job displacement. the risky job of being back to work. European Economic Review, 61(0):205 - 216, 2013.

Assar Lindbeck and Dennis J Snower. Insiders versus outsiders. Journal of Economic Perspectives, pages 165-188, 2001.

Hani Mansour. The career effects of graduating from college in a bad economy: The role of workersâ ability. University of Colorado Denver unpublished manuscript, 2009.

OECD. Employment outlook, 1999.

OECD. Employment outlook, 2004.

Philip Oreopoulos, Till von Wachter, and Andrew Heisz. The short-and long-term career effects of graduating in a recession. American Economic Journal: Applied Economics, $4(1): 1-29,2012$.

Paul Oyer. Initial labor market conditions and long-term outcomes for economists. Journal of Economic Perspectives, 20(3):143-160, Summer 2006.

Oddbjørn Raaum and Knut Røed. Do business cycle conditions at the time of labor market entry affect future employment prospects? The Review of Economics and Statistics, 88(2):193-210, 2006.

Carl Shapiro and Joseph E. Stiglitz. Equilibrium unemployment as a worker discipline device. The American Economic Review, 74(3):433-444, June 1984. 
Jody L. Sindelar, Jason Fletcher, Tracy Falba, Patricia Keenan, and William T. Gallo. Impact of first occupation on health at older ages. NBER Working Papers 13715, National Bureau of Economic Research, Inc, December 2007.

Gary Solon, Warren Whatley, and Ann Huff Stevens. Wage changes and intrafirm job mobility over the business cycle: Two case studies. Industrial and Labor Relations Review, 50(3):402-415, April 1997.

Figure 1: National and regional unemployment rates, 1994-2003.

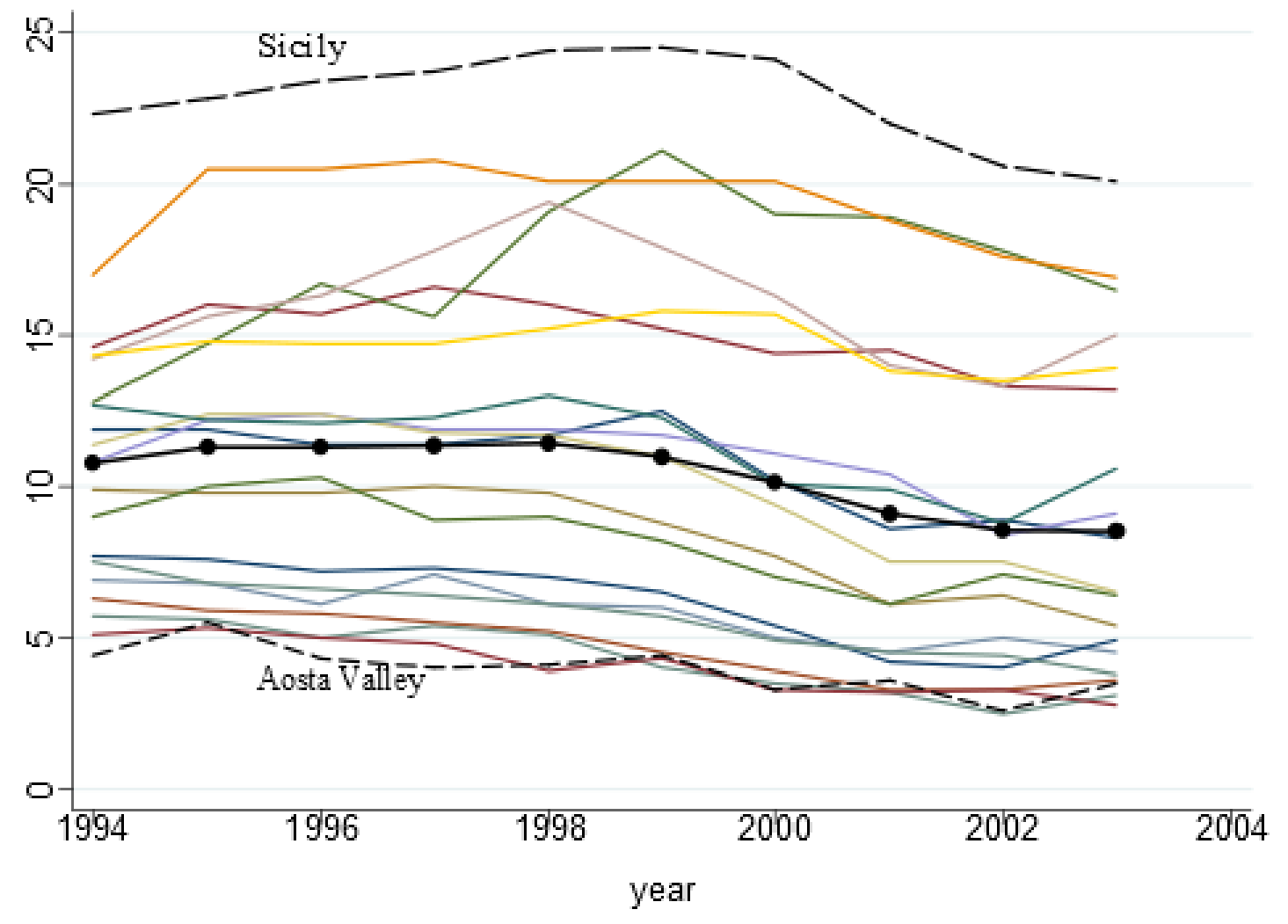

$\longrightarrow$ National unemployment rate

Source ISTAT. 
Figure 2: Residual unemployment rates, 1994-2003.

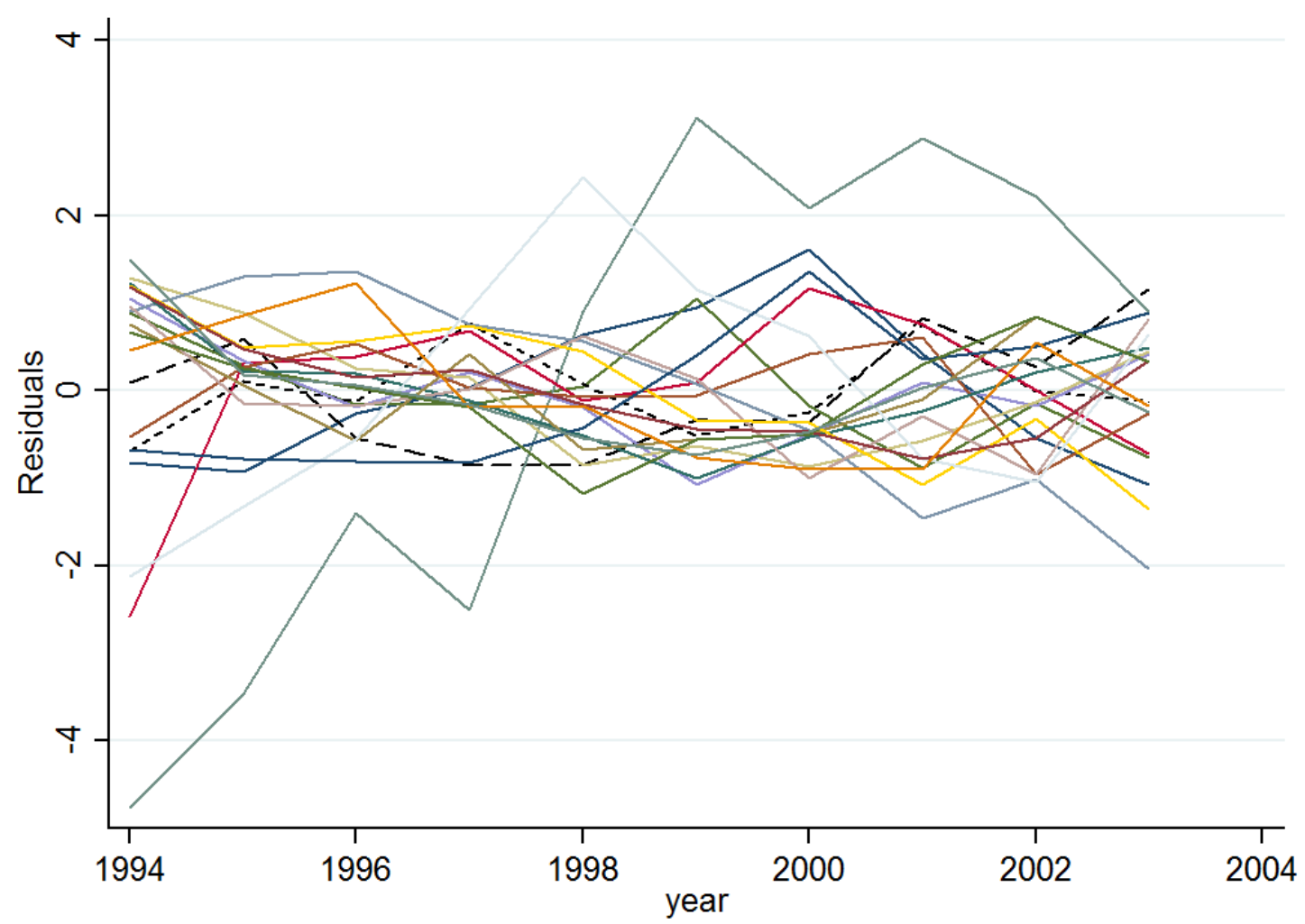

The lines represent the region-specific residuals from a regression of regional unemployment rate on year and region dummies. 
Figure 3: Effect of $u r_{0}$ on log wages, wage index, log annual earnings and log weeks worked

(a) Log weekly wages

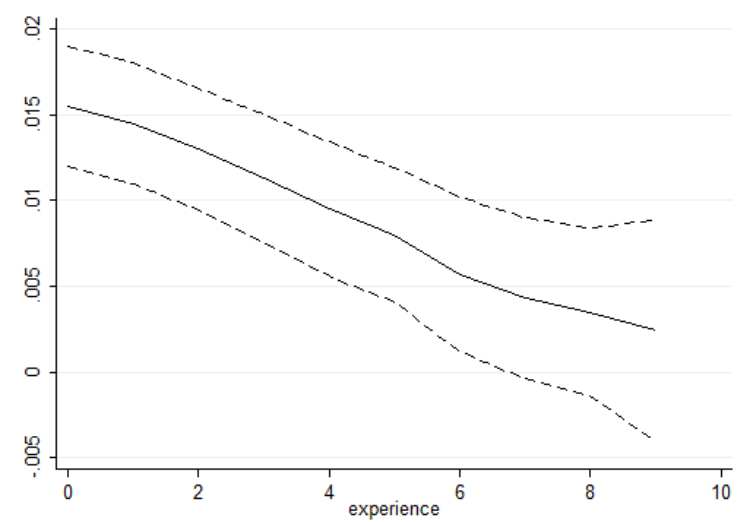

(c) Log annual earnings

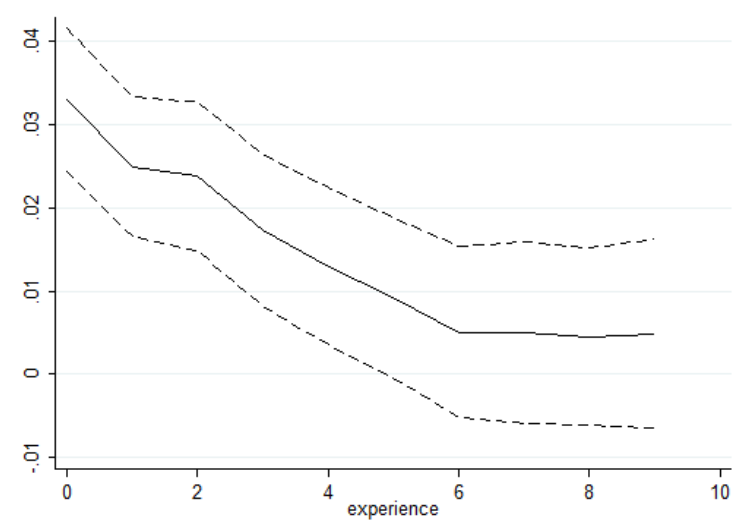

(b) Log wage index

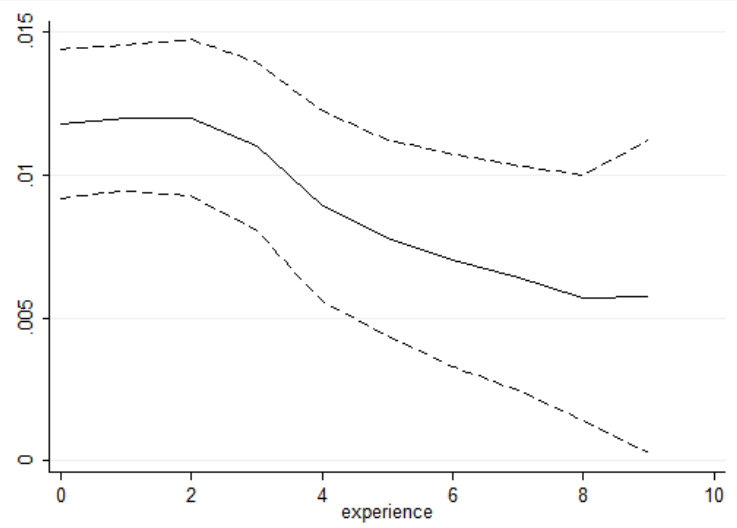

(d) Log annual weeks worked

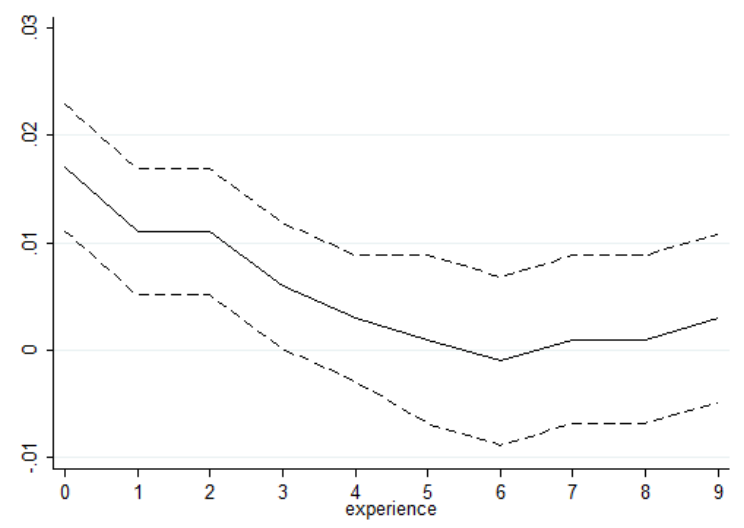

Note: The solid line represents the effect of $u r_{0}$ by year of experience. The dotted lines show the $95 \%$ confidence intervals. 


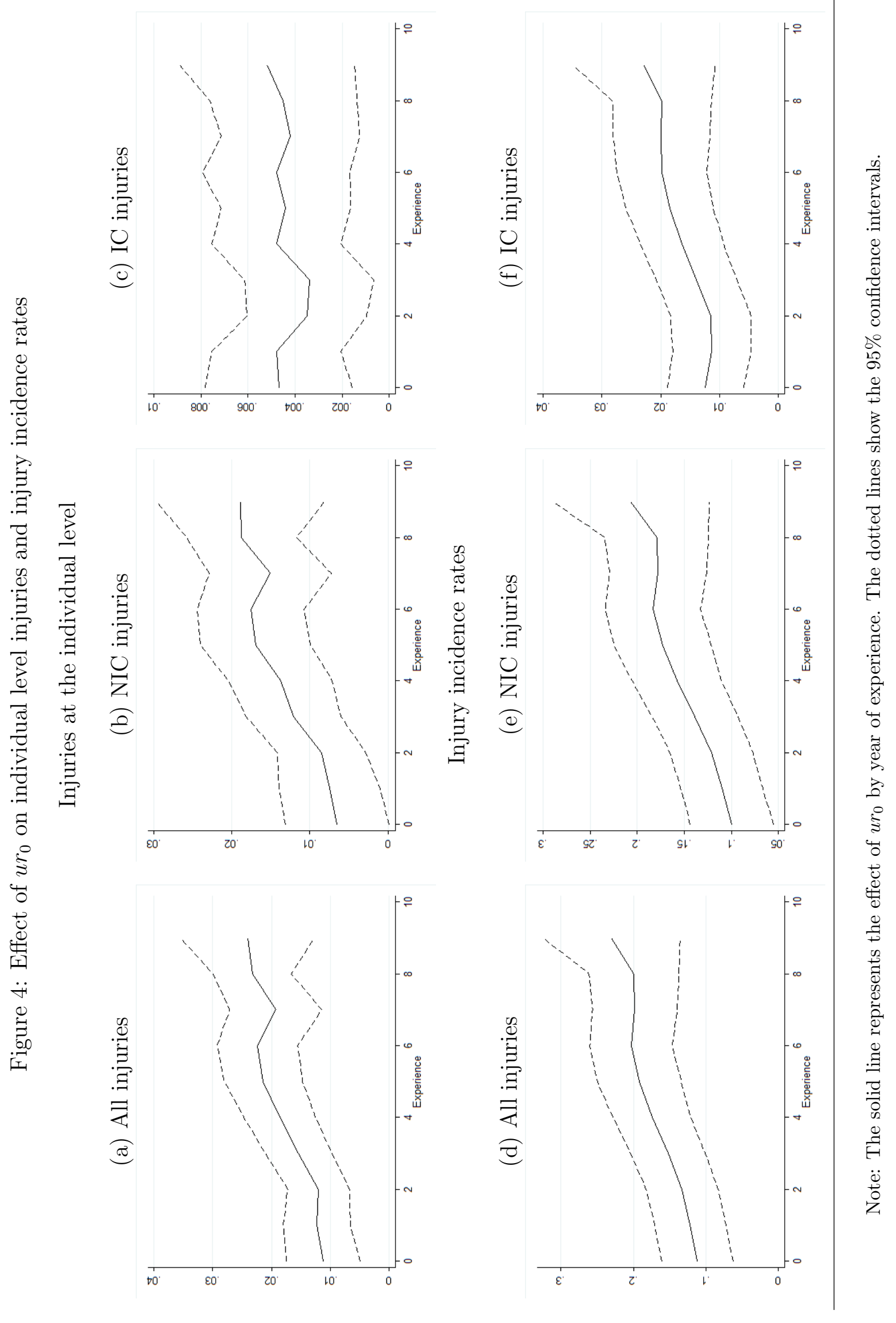




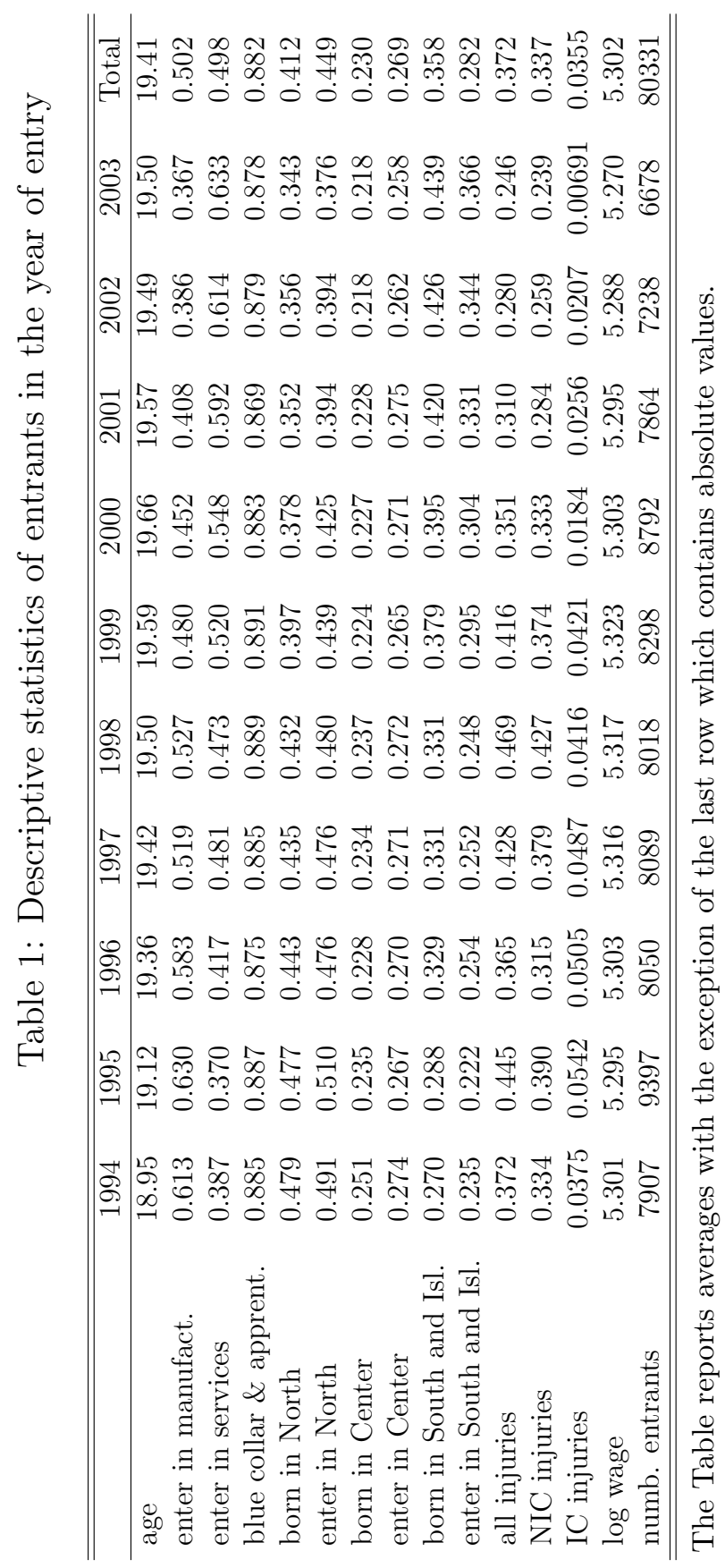




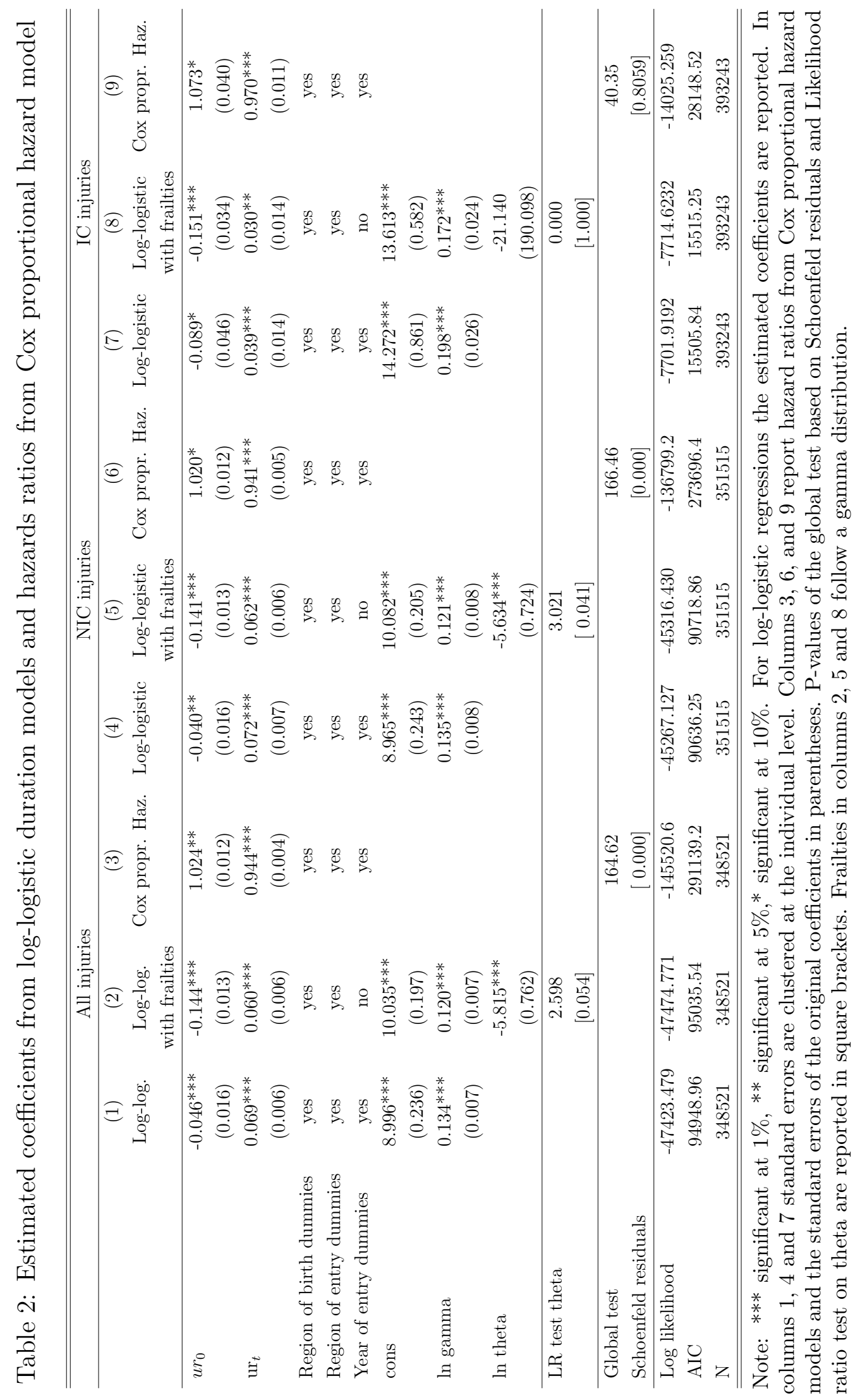


Table 3: The effect of labor market conditions on the age at entry, the probability of being a high school student, the probability of being a university student and the probability of starting working in a region different from the region of birth

\begin{tabular}{|c|c|c|c|c|c|}
\hline & $\begin{array}{c}(1) \\
\mathrm{age}_{0}\end{array}$ & $\begin{array}{c}(2) \\
\text { High School student }\end{array}$ & $\begin{array}{c}\text { (3) } \\
\text { University student }\end{array}$ & $\begin{array}{c}\text { (4) } \\
\text { mobility }\end{array}$ & $\begin{array}{c}(5) \\
\text { mobility }\end{array}$ \\
\hline \multicolumn{6}{|l|}{ main } \\
\hline$u_{0}$ & $\begin{array}{r}0.044^{* * *} \\
(0.016)\end{array}$ & & & & \\
\hline $\mathrm{ur}_{t}$ & & $\begin{array}{l}0.018 \\
(0.034)\end{array}$ & $\begin{array}{l}-0.006 \\
(0.006)\end{array}$ & & \\
\hline $\operatorname{ur}_{N}$ & & & & $\begin{array}{c}0.106^{* * *} \\
(0.019)\end{array}$ & $\begin{array}{c}0.005 \\
(0.096)\end{array}$ \\
\hline region fixed effect & yes & yes & yes & no & yes \\
\hline year fixed effect & yes & yes & yes & no & yes \\
\hline$N$ & 80331 & 143009 & 196150 & 80331 & 80331 \\
\hline$R^{2}$ & 0.082 & & & & \\
\hline
\end{tabular}

Note: The results of column 1 are based on a OLS regression, all the other columns report the results of logistic regressions. $u r_{0}$ refers to the unemployment rate of the region of entry in the year of entry; $u r_{N}$ is the unemployment rate of the region of birth in the year of entry; $u r_{t}$ is the contemporaneous unemployment rate in the region of residence. Robust standard errors in parentheses are clustered by region of entry per year of entry. ${ }^{* * *}$ significant at $1 \%,{ }^{* *}$ significant at $5 \%,{ }^{*}$ significant at $10 \%$.

Table 4: Distribution of entrants by macro-region of birth and macro-region of entry

\begin{tabular}{lcccc}
\hline \hline Region of birth & $\begin{array}{c}\text { \% of entrants in region } \\
\text { different from reg. of birth }\end{array}$ & \% of entr. in North & \% of entr. in Center & $\begin{array}{c}\text { \% of entr. in South } \\
\text { and Islands }\end{array}$ \\
\hline North & 7.6 & 96.4 & 2.2 & 1.4 \\
Center & 8.4 & 3.0 & 94.8 & 2.2 \\
South and Isl. & 27.0 & 12.6 & 11.5 & 75.9 \\
\hline \hline
\end{tabular}


Table 5: The effect on initial and contemporaneous labor market conditions on job and firm characteristics

\begin{tabular}{|c|c|c|c|c|c|}
\hline & (1) & $\overline{(2)}$ & $\overline{(3)}$ & (4) & $(\overline{(5)}$ \\
\hline \multirow{3}{*}{$\psi_{1}$} & Apprentice & Blue collar & White collar & Aver. numb. of employees & Year of firm birth \\
\hline & -0.0103 & -0.0072 & $0.0180^{* * *}$ & $-491.1111^{* * *}$ & $-0.6851^{* * *}$ \\
\hline & $(0.0103)$ & $(0.0096)$ & $(0.0057)$ & $(122.0646)$ & $(0.1772)$ \\
\hline \multirow[t]{2}{*}{$\psi_{2}$} & $-0.0598^{* * *}$ & 0.0140 & $0.0467^{* * *}$ & $-652.4799^{* * *}$ & $-1.2554^{* * *}$ \\
\hline & $(0.0203)$ & $(0.0185)$ & $(0.0114)$ & $(212.3137)$ & $(0.3439)$ \\
\hline \multirow[t]{2}{*}{$\psi_{3}$} & $-0.1767^{* * *}$ & $0.0950^{* * *}$ & $0.0830^{* * *}$ & $-627.2470^{* *}$ & $-1.8567^{* * *}$ \\
\hline & $(0.0294)$ & $(0.0272)$ & $(0.0165)$ & $(282.5111)$ & $(0.4954)$ \\
\hline \multirow[t]{2}{*}{$\psi_{4}$} & $-0.2939^{* * *}$ & $0.1788^{* * *}$ & $0.1165^{* * *}$ & -601.0239 & $-2.3321^{* * *}$ \\
\hline & $(0.0392)$ & $(0.0368)$ & $(0.0217)$ & $(368.5376)$ & $(0.6595)$ \\
\hline \multirow[t]{2}{*}{$\psi_{5}$} & $-0.3787^{* * *}$ & $0.2430^{* * *}$ & $0.1366^{* * *}$ & -636.5541 & $-2.9501^{* * *}$ \\
\hline & $(0.0479)$ & $(0.0449)$ & $(0.0273)$ & $(458.9337)$ & $(0.8189)$ \\
\hline \multirow[t]{2}{*}{$\psi_{6}$} & $-0.4311^{* * *}$ & $0.2686^{* * *}$ & $0.1636^{* * *}$ & -689.9521 & $-3.7899^{* * *}$ \\
\hline & $(0.0572)$ & $(0.0535)$ & $(0.0322)$ & $(546.7727)$ & $(0.9621)$ \\
\hline \multirow[t]{2}{*}{$\psi_{7}$} & $-0.4765^{* * *}$ & $0.3051^{* * *}$ & $0.1712^{* * *}$ & -627.2085 & $-4.1091^{* * *}$ \\
\hline & $(0.0664)$ & $(0.0621)$ & $(0.0383)$ & $(653.4127)$ & (1.1817) \\
\hline \multirow[t]{2}{*}{$\psi_{8}$} & $-0.5166^{* * *}$ & $0.3273^{* * *}$ & $0.1880^{* * *}$ & -561.3404 & $-4.3434^{* * *}$ \\
\hline & $(0.0800)$ & $(0.0725)$ & $(0.0443)$ & $(758.3805)$ & $(1.3470)$ \\
\hline \multirow[t]{2}{*}{$\psi_{9}$} & $-0.5382^{* * *}$ & $0.3158^{* * *}$ & $0.2187^{* * *}$ & -371.1938 & $-4.6681^{* * *}$ \\
\hline & $(0.1060)$ & $(0.0805)$ & $(0.0575)$ & $(824.4677)$ & $(1.5256)$ \\
\hline \multirow[t]{2}{*}{$\beta_{0}$} & $-0.0212^{* * *}$ & $0.0211^{* * *}$ & 0.0001 & -20.2449 & -0.0274 \\
\hline & $(0.0024)$ & $(0.0022)$ & $(0.0013)$ & $(32.8142)$ & $(0.0507)$ \\
\hline \multirow[t]{2}{*}{$\beta_{1}$} & $-0.0205^{* * *}$ & $0.0207^{* * *}$ & -0.0002 & 12.9736 & -0.0277 \\
\hline & $(0.0023)$ & $(0.0021)$ & $(0.0013)$ & $(32.9913)$ & $(0.0500)$ \\
\hline \multirow[t]{2}{*}{$\beta_{2}$} & $-0.0196^{* * *}$ & $0.0208^{* * *}$ & -0.0011 & 28.8675 & -0.0379 \\
\hline & $(0.0022)$ & $(0.0021)$ & $(0.0013)$ & $(32.5239)$ & $(0.0499)$ \\
\hline \multirow[t]{2}{*}{$\beta_{3}$} & $-0.0164^{* * *}$ & $0.0189^{* * *}$ & $-0.0024^{*}$ & 34.4513 & -0.0266 \\
\hline & $(0.0023)$ & $(0.0021)$ & $(0.0014)$ & $(33.0310)$ & $(0.0488)$ \\
\hline \multirow[t]{2}{*}{$\beta_{4}$} & $-0.0131^{* * *}$ & $0.0173^{* * *}$ & $-0.0040^{* * *}$ & 41.4381 & -0.0217 \\
\hline & $(0.0024)$ & $(0.0022)$ & $(0.0014)$ & $(32.3806)$ & $(0.0506)$ \\
\hline \multirow[t]{2}{*}{$\beta_{5}$} & $-0.0108^{* * *}$ & $0.0157^{* * *}$ & $-0.0047^{* * *}$ & 46.3484 & -0.0046 \\
\hline & $(0.0025)$ & $(0.0023)$ & $(0.0014)$ & $(35.2471)$ & $(0.0524)$ \\
\hline \multirow[t]{2}{*}{$\beta_{6}$} & $-0.0093^{* * *}$ & $0.0157^{* * *}$ & $-0.0063^{* * *}$ & 54.0599 & 0.0389 \\
\hline & $(0.0028)$ & $(0.0025)$ & $(0.0015)$ & $(35.9684)$ & $(0.0515)$ \\
\hline \multirow[t]{2}{*}{$\beta_{7}$} & $-0.0078^{* *}$ & $0.0140^{* * *}$ & $-0.0060^{* * *}$ & 47.0341 & 0.0342 \\
\hline & $(0.0031)$ & $(0.0030)$ & $(0.0015)$ & $(36.3415)$ & $(0.0546)$ \\
\hline \multirow[t]{2}{*}{$\beta_{8}$} & $-0.0070^{* *}$ & $0.0138^{* * *}$ & $-0.0065^{* * *}$ & 50.8119 & 0.0302 \\
\hline & $(0.0034)$ & $(0.0032)$ & $(0.0015)$ & $(34.7873)$ & $(0.0576)$ \\
\hline \multirow[t]{2}{*}{$\beta_{9}$} & $-0.0073^{*}$ & $0.0163^{* * *}$ & $-0.0085^{* * *}$ & 58.9073 & 0.0384 \\
\hline & $(0.0039)$ & $(0.0029)$ & $(0.0023)$ & $(37.2060)$ & $(0.0667)$ \\
\hline \multirow[t]{2}{*}{$\phi$} & -0.0006 & -0.0014 & $0.0020^{* * *}$ & $-40.4455^{* * *}$ & $0.1726^{* * *}$ \\
\hline & $(0.0008)$ & $(0.0009)$ & $(0.0005)$ & $(12.1242)$ & $(0.0221)$ \\
\hline$N$ & 362682 & 362682 & 362682 & 345849 & 346105 \\
\hline$R^{2}$ & 0.125 & 0.069 & 0.034 & 0.013 & 0.056 \\
\hline
\end{tabular}

Note: Robust standard errors in parentheses are clustered by region of entry per year of entry. ${ }^{*} * *$ significant at $1 \%,{ }^{* *}$ significant at $5 \%,{ }^{*}$ significant at $10 \%$. Regressions include dummies for year of entry, region of entry, region of birth and current year. See equation 1 for the interpretation of $\phi, \beta$ and $\psi$ coefficients. 
Figure 5: Effect of $u r_{0}$ on log wage distribution
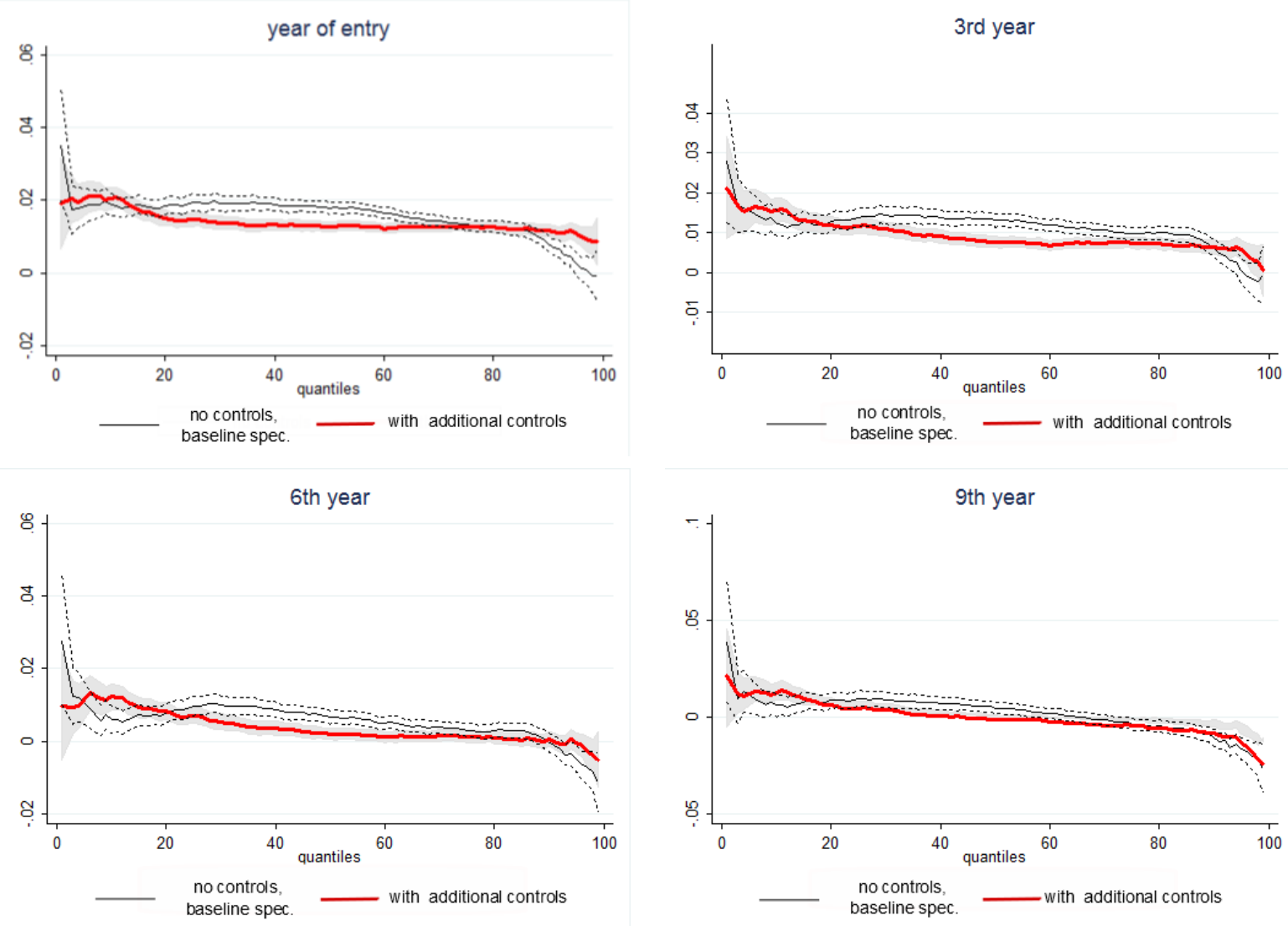

Note: The solid lines represent the effect of $u r_{0}$ on the percentiles of the log wage distribution by year of experience. All regressions include dummies for year of entry, region of entry, region of birth and current year. The black line represents the estimated effect of $u r_{0}$ in the baseline specification. The red line represents the estimated effect of $u r_{0}$ after the inclusion of additional controls such as initial firm attributes (sector, average number of employees, age) and type of occupation. The grey area and the dotted lines show the $95 \%$ confidence intervals. 
Table 6: The effect of initial and contemporaneous labor market conditions on the probability of working in the entry firm, the probability of changing firm, tenure and the probability of being non-employed

\begin{tabular}{|c|c|c|c|c|}
\hline & (1) & (2) & (3) & (4) \\
\hline & Entry firm & Change firm & Tenure & Non-Employed \\
\hline \multirow[t]{2}{*}{$\psi_{2}$} & $-0.2107^{* * *}$ & $0.0611^{* * *}$ & $0.4812^{* * *}$ & 0.0000 \\
\hline & $(0.0161)$ & $(0.0060)$ & $(0.0199)$ & $(0.0065)$ \\
\hline \multirow[t]{2}{*}{$\psi_{3}$} & $-0.2631^{* * *}$ & -0.0081 & $0.9921^{* * *}$ & $-0.0255^{* *}$ \\
\hline & $(0.0202)$ & $(0.0097)$ & $(0.0409)$ & $(0.0120)$ \\
\hline \multirow[t]{2}{*}{$\psi_{4}$} & $-0.2746^{* * *}$ & $-0.0494^{* * *}$ & $1.5302^{* * *}$ & $-0.0338^{* *}$ \\
\hline & $(0.0202)$ & $(0.0132)$ & $(0.0623)$ & $(0.0168)$ \\
\hline \multirow[t]{2}{*}{$\psi_{5}$} & $-0.2532^{* * *}$ & $-0.0897^{* * *}$ & $2.0817^{* * *}$ & -0.0307 \\
\hline & $(0.0247)$ & $(0.0162)$ & $(0.0770)$ & $(0.0226)$ \\
\hline \multirow[t]{2}{*}{$\psi_{6}$} & $-0.2646^{* * *}$ & $-0.1120^{* * *}$ & $2.6116^{* * *}$ & -0.0250 \\
\hline & $(0.0234)$ & $(0.0193)$ & $(0.1012)$ & $(0.0284)$ \\
\hline \multirow[t]{2}{*}{$\psi_{7}$} & $-0.2526^{* * *}$ & $-0.1200^{* * *}$ & $3.0923^{* * *}$ & -0.0188 \\
\hline & $(0.0367)$ & $(0.0238)$ & $(0.1297)$ & $(0.0343)$ \\
\hline \multirow[t]{2}{*}{$\psi_{8}$} & $-0.2472^{* * *}$ & $-0.1409^{* * *}$ & $3.6124^{* * *}$ & -0.0004 \\
\hline & $(0.0333)$ & $(0.0278)$ & $(0.1471)$ & $(0.0389)$ \\
\hline \multirow[t]{2}{*}{$\psi_{9}$} & $-0.2127^{* * *}$ & $-0.1570^{* * *}$ & $4.2220^{* * *}$ & 0.0032 \\
\hline & $(0.0333)$ & $(0.0388)$ & $(0.2066)$ & $(0.0389)$ \\
\hline \multirow[t]{2}{*}{$\beta_{1}$} & 0.0011 & $-0.0059^{* * *}$ & 0.0093 & $-0.0303^{* * *}$ \\
\hline & $(0.0036)$ & $(0.0014)$ & $(0.0085)$ & $(0.0025)$ \\
\hline \multirow[t]{2}{*}{$\beta_{2}$} & 0.0003 & $-0.0046^{* * *}$ & $0.0173^{* *}$ & $-0.0240^{* * *}$ \\
\hline & $(0.0036)$ & $(0.0014)$ & $(0.0082)$ & $(0.0024)$ \\
\hline \multirow[t]{2}{*}{$\beta_{3}$} & -0.0016 & -0.0003 & $0.0153^{*}$ & $-0.0210^{* * *}$ \\
\hline & $(0.0036)$ & $(0.0015)$ & $(0.0083)$ & $(0.0025)$ \\
\hline \multirow[t]{2}{*}{$\beta_{4}$} & -0.0021 & 0.0015 & 0.0094 & $-0.0200^{* * *}$ \\
\hline & $(0.0038)$ & $(0.0015)$ & $(0.0088)$ & $(0.0026)$ \\
\hline \multirow[t]{2}{*}{$\beta_{5}$} & -0.0037 & $0.0031^{* *}$ & -0.0014 & $-0.0200^{* * *}$ \\
\hline & $(0.0037)$ & $(0.0015)$ & $(0.0084)$ & $(0.0027)$ \\
\hline \multirow[t]{2}{*}{$\beta_{6}$} & -0.0034 & $0.0037^{* *}$ & -0.0113 & $-0.0209^{* * *}$ \\
\hline & $(0.0038)$ & $(0.0016)$ & $(0.0088)$ & $(0.0028)$ \\
\hline \multirow[t]{2}{*}{$\beta_{7}$} & -0.0030 & 0.0022 & -0.0141 & $-0.0210^{* * *}$ \\
\hline & $(0.0045)$ & $(0.0017)$ & $(0.0100)$ & $(0.0028)$ \\
\hline \multirow[t]{2}{*}{$\beta_{8}$} & -0.0030 & $0.0029^{*}$ & $-0.0221^{*}$ & $-0.0227^{* * *}$ \\
\hline & $(0.0045)$ & $(0.0017)$ & $(0.0114)$ & $(0.0027)$ \\
\hline \multirow[t]{2}{*}{$\beta_{9}$} & -0.0034 & $0.0034^{* *}$ & $-0.0369^{* * *}$ & $-0.0227^{* * *}$ \\
\hline & $(0.0045)$ & $(0.0017)$ & $(0.0133)$ & $(0.0029)$ \\
\hline \multirow[t]{2}{*}{$\phi$} & $0.0039^{* *}$ & $-0.0040^{* *}$ & $0.0296^{* * *}$ & $0.0347^{* * *}$ \\
\hline & $(0.0019)$ & $(0.0019)$ & $(0.0104)$ & $(0.0025)$ \\
\hline$N$ & 282351 & 282351 & 282351 & 373847 \\
\hline$R^{2}$ & 0.196 & 0.017 & 0.253 & 0.075 \\
\hline
\end{tabular}

Note: Robust standard errors in parentheses are clustered by region of entry per year of entry. significant at $1 \%,{ }^{* *}$ significant at $5 \%,{ }^{*}$ significant at $10 \%$. Regressions include dummies for year of entry, region of entry, region of birth and current year. See equation 1 for the interpretation of $\phi, \beta$ and $\psi$ coefficients. 


\section{A Appendix}

Figure A1: Log mean wage by year of experience for different cohorts of entrants

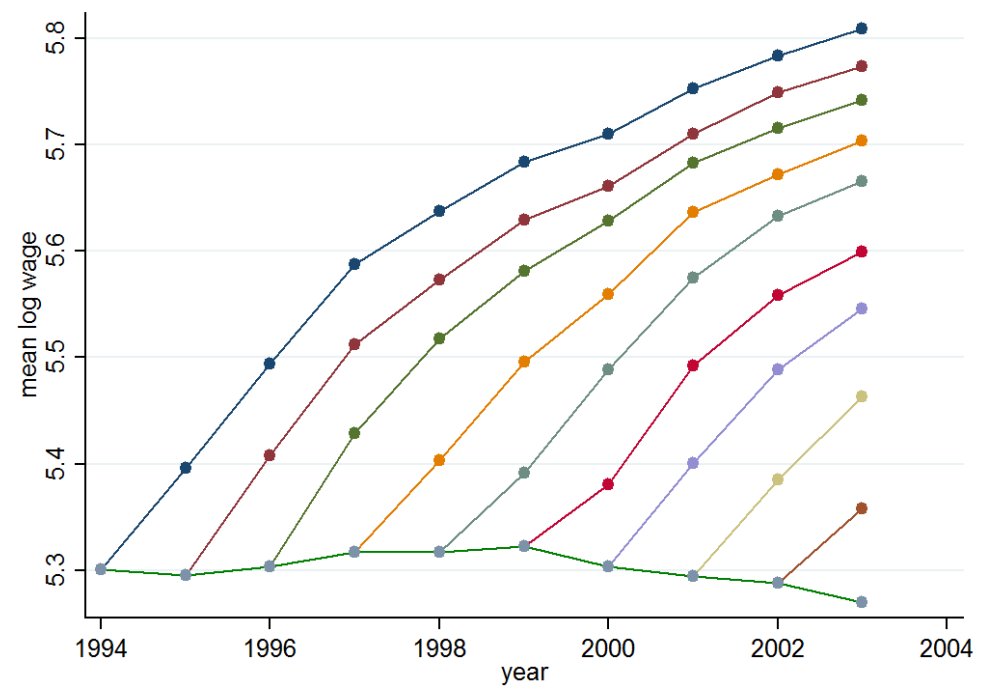

This figure shows the mean log wages by year of experience for cohorts or workers entered in different years. The bottom green line represents mean log wage in the year of entry.

Figure A2: Estimated hazards by log-logistic and Cox proportional hazard model, all injuries

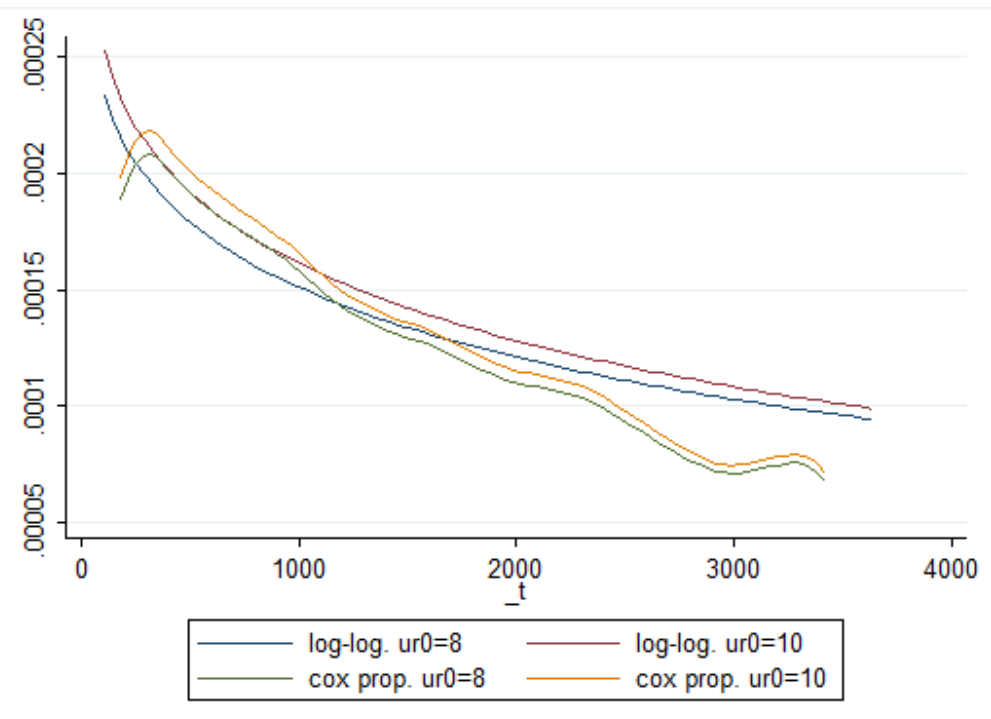


Figure A3: Mean log entry wages, ECHP

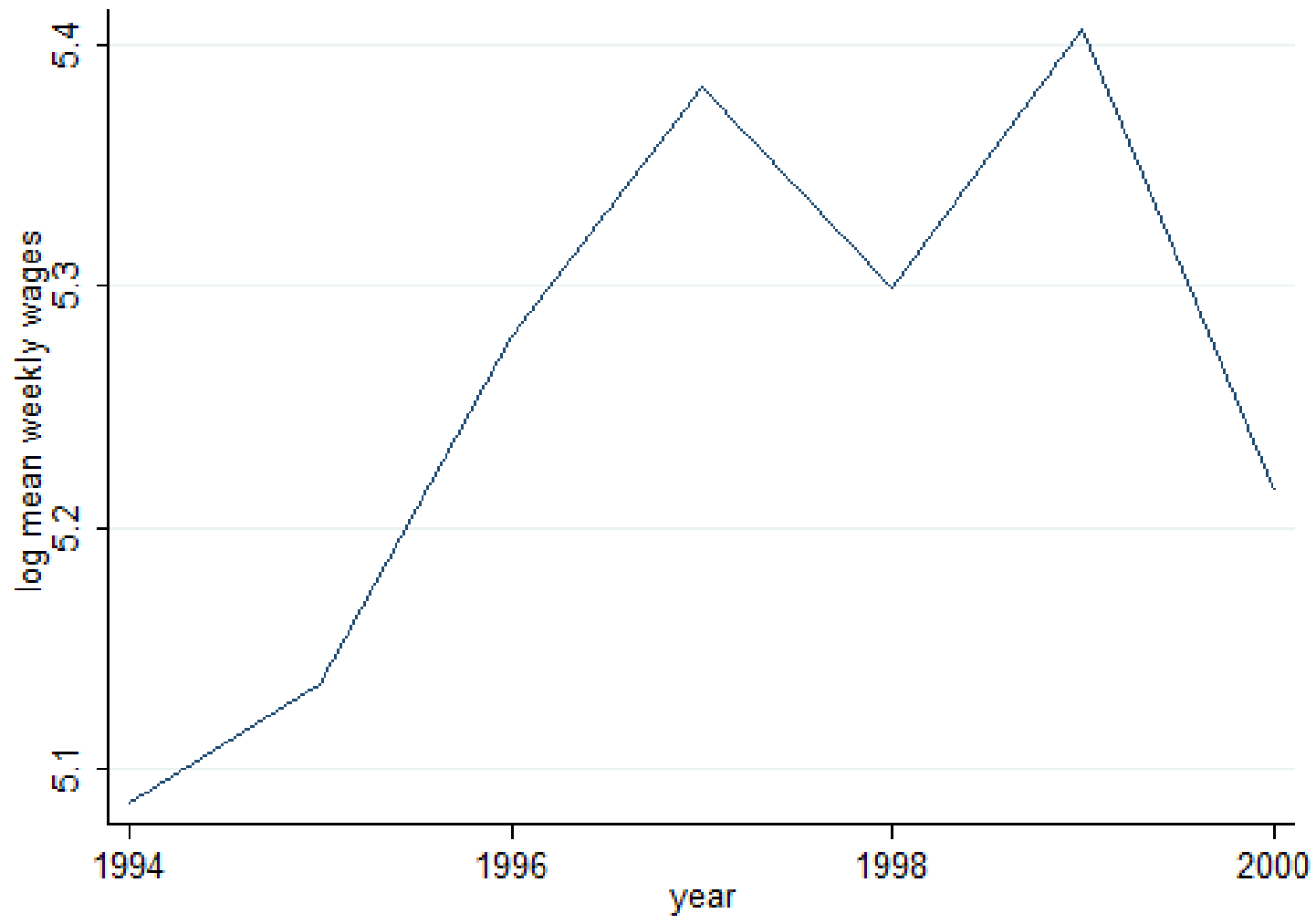

Source: Authors' computation from ECHP data. This figure shows the mean log wages in the year of entry for different cohorts in the period 1994-2000. The sample includes entrants who respect the selection criteria described in the data section. The weekly wages are computed dividing the real gross monthly salary earnings by the notional number of weeks in a month. The weekly wages are reported on a full time equivalent scale using the information about the amount of hours worked in a week. 
Figure A4: Effect of $u r_{0}$ on weekly wages and individual level injuries for stayers in the entry firm and movers

(a) Log weekly wages

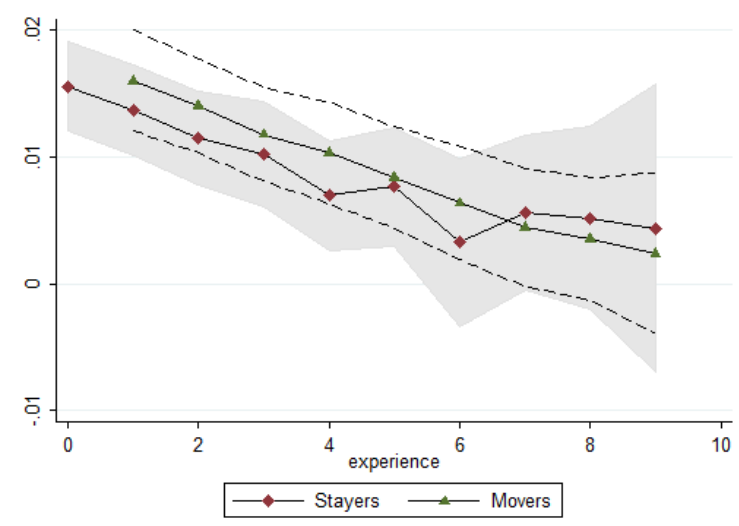

(c) NIC injuries

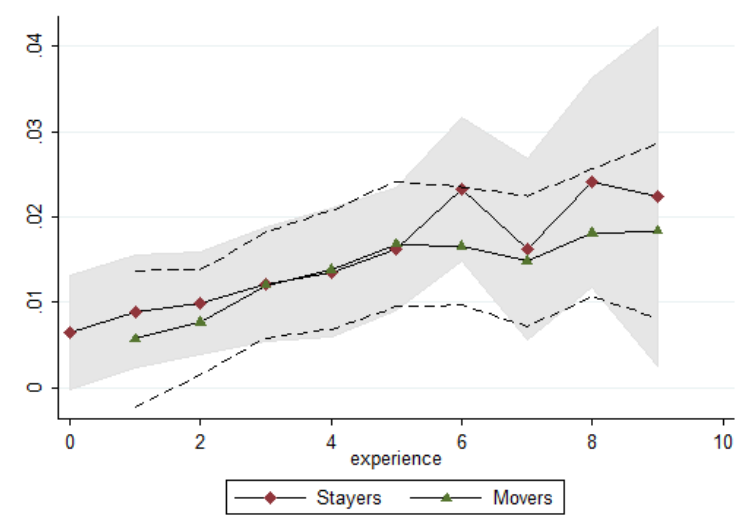

(b) All injuries

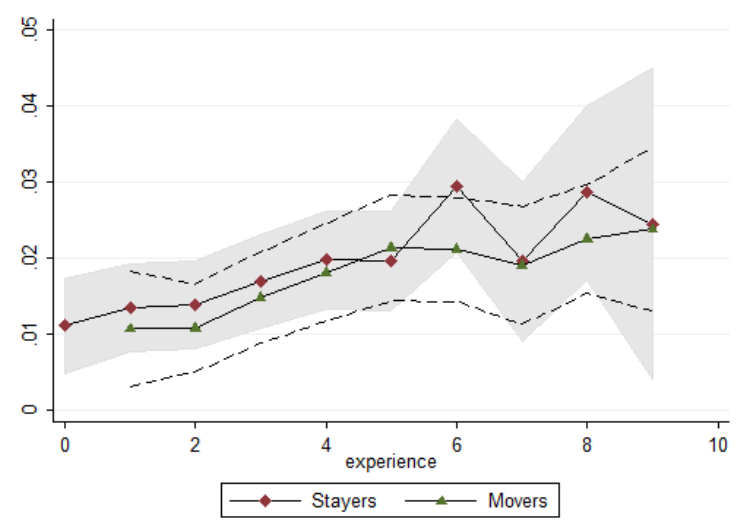

(d) IC injuries

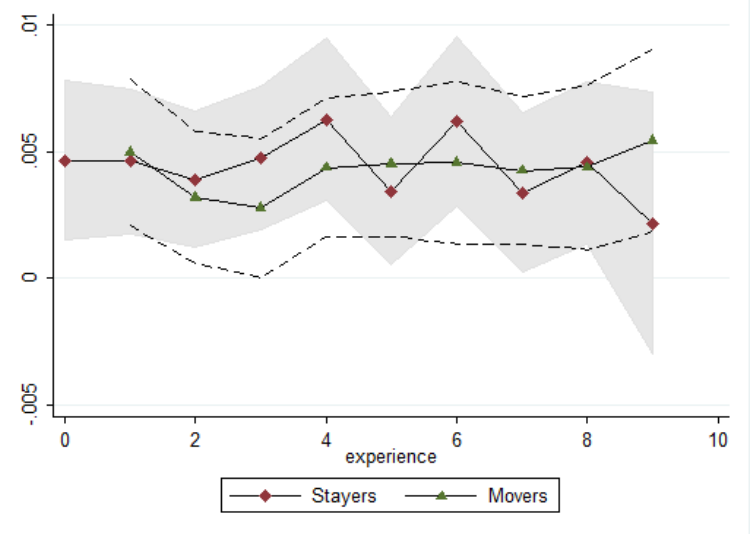

Note: The grey area and the dotted lines represent the $95 \%$ confidence intervals for stayers and movers, respectively. Stayers are individuals who remain with the first employer. Movers are individuals who move out from the first employer. Robust standard errors are clustered by region of entry per year of entry. Regressions include dummies for year of entry, region of entry, region of birth and current year. 
Table A1: The effect of initial and contemporaneous labor market conditions on log weekly wage, weekly wage index, annual earnings, annual weeks worked

\begin{tabular}{|c|c|c|c|c|}
\hline & $(1)$ & $(2)$ & (3) & $(4)$ \\
\hline & $\ln$ (wage) & $\ln$ (wage index) & $\ln$ (earnings) & $\ln ($ weeks worked $)$ \\
\hline \multirow[t]{2}{*}{$\psi_{1}$} & $0.106^{* * *}$ & 0.005 & $0.860^{* * *}$ & $0.754^{* * *}$ \\
\hline & $(0.008)$ & $(0.006)$ & $(0.016)$ & $(0.012)$ \\
\hline \multirow[t]{2}{*}{$\psi_{2}$} & $0.222^{* * *}$ & $0.030^{* * *}$ & $1.038^{* * *}$ & $0.816^{* * *}$ \\
\hline & $(0.013)$ & $(0.010)$ & $(0.027)$ & $(0.018)$ \\
\hline \multirow[t]{2}{*}{$\psi_{3}$} & $0.316^{* * *}$ & $0.080^{* * *}$ & $1.256^{* * *}$ & $0.939^{* * *}$ \\
\hline & $(0.018)$ & $(0.014)$ & $(0.039)$ & $(0.026)$ \\
\hline \multirow[t]{2}{*}{$\psi_{4}$} & $0.401^{* * *}$ & $0.131^{* * *}$ & $1.409^{* * *}$ & $1.008^{* * *}$ \\
\hline & $(0.024)$ & $(0.019)$ & $(0.053)$ & $(0.036)$ \\
\hline \multirow[t]{2}{*}{$\psi_{5}$} & $0.468^{* * *}$ & $0.170^{* * *}$ & $1.558^{* * *}$ & $1.090 * * *$ \\
\hline & $(0.029)$ & $(0.023)$ & $(0.066)$ & $(0.044)$ \\
\hline \multirow[t]{2}{*}{$\psi_{6}$} & $0.536^{* * *}$ & $0.196^{* * *}$ & $1.687^{* * *}$ & $1.152^{* * *}$ \\
\hline & $(0.035)$ & $(0.028)$ & $(0.081)$ & $(0.053)$ \\
\hline \multirow[t]{2}{*}{$\psi_{7}$} & $0.592^{* * *}$ & $0.217^{* * *}$ & $1.761^{* * *}$ & $1.169^{* * *}$ \\
\hline & $(0.039)$ & $(0.033)$ & $(0.091)$ & $(0.059)$ \\
\hline \multirow[t]{2}{*}{$\psi_{8}$} & $0.644^{* * *}$ & $0.239^{* * *}$ & $1.824^{* * *}$ & $1.180^{* * *}$ \\
\hline & $(0.046)$ & $(0.039)$ & $(0.106)$ & $(0.068)$ \\
\hline \multirow[t]{2}{*}{$\psi_{9}$} & $0.697^{* * *}$ & $0.252^{* * *}$ & $1.863^{* * *}$ & $1.167^{* * *}$ \\
\hline & $(0.055)$ & $(0.047)$ & $(0.122)$ & $(0.074)$ \\
\hline \multirow[t]{2}{*}{$\beta_{0}$} & $0.016^{* * *}$ & $0.012^{* * *}$ & $0.033^{* * *}$ & $0.017^{* * *}$ \\
\hline & $(0.002)$ & $(0.001)$ & $(0.004)$ & $(0.003)$ \\
\hline \multirow[t]{2}{*}{$\beta_{1}$} & $0.015^{* * *}$ & $0.012^{* * *}$ & $0.025^{* * *}$ & $0.011^{* * *}$ \\
\hline & $(0.002)$ & $(0.001)$ & $(0.004)$ & $(0.003)$ \\
\hline \multirow[t]{2}{*}{$\beta_{2}$} & $0.013^{* * *}$ & $0.012^{* * *}$ & $0.024^{* * *}$ & $0.011^{* * *}$ \\
\hline & $(0.002)$ & $(0.001)$ & $(0.005)$ & $(0.003)$ \\
\hline \multirow[t]{2}{*}{$\beta_{3}$} & $0.011^{* * *}$ & $0.011^{* * *}$ & $0.017^{* * *}$ & $0.006^{*}$ \\
\hline & $(0.002)$ & $(0.002)$ & $(0.005)$ & $(0.003)$ \\
\hline \multirow[t]{2}{*}{$\beta_{4}$} & $0.010 * * *$ & $0.009^{* * *}$ & $0.013^{* * *}$ & 0.003 \\
\hline & $(0.002)$ & $(0.002)$ & $(0.005)$ & $(0.003)$ \\
\hline \multirow[t]{2}{*}{$\beta_{5}$} & $0.008^{* * *}$ & $0.008^{* * *}$ & $0.009^{*}$ & 0.001 \\
\hline & $(0.002)$ & $(0.002)$ & $(0.005)$ & $(0.004)$ \\
\hline \multirow[t]{2}{*}{$\beta_{6}$} & $0.006^{* *}$ & $0.007^{* * *}$ & 0.005 & -0.001 \\
\hline & $(0.002)$ & $(0.002)$ & $(0.005)$ & $(0.004)$ \\
\hline \multirow[t]{2}{*}{$\beta_{7}$} & $0.004^{*}$ & $0.006^{* * *}$ & 0.005 & 0.001 \\
\hline & $(0.002)$ & $(0.002)$ & $(0.006)$ & $(0.004)$ \\
\hline \multirow[t]{2}{*}{$\beta_{8}$} & 0.003 & $0.006^{* *}$ & 0.005 & 0.001 \\
\hline & $(0.003)$ & $(0.002)$ & $(0.005)$ & $(0.004)$ \\
\hline \multirow[t]{2}{*}{$\beta_{9}$} & 0.002 & $0.006^{* *}$ & 0.005 & 0.003 \\
\hline & $(0.003)$ & $(0.003)$ & $(0.006)$ & $(0.004)$ \\
\hline \multirow[t]{2}{*}{$\phi$} & $-0.008^{* * *}$ & $-0.007 * * *$ & $-0.008^{* * *}$ & 0.000 \\
\hline & $(0.001)$ & $(0.000)$ & $(0.002)$ & $(0.002)$ \\
\hline$N$ & 362682 & 362682 & 362682 & 362682 \\
\hline$R^{2}$ & 0.163 & 0.159 & 0.290 & 0.236 \\
\hline
\end{tabular}

Note: $* * *$ significant at $1 \%,{ }^{*} *$ significant at $5 \%,{ }^{*}$ significant at $10 \%$. Robust standard errors in parentheses are clustered by region of entry per year of entry. Regressions include dummies for year of entry, region of entry, region of birth and current year. See equation 1 for the interpretation of $\phi, \beta$ and $\psi$ coefficients. 
Table A2: The effect of initial and contemporaneous labor market conditions on individual level injuries and injury incidence rates

\begin{tabular}{|c|c|c|c|c|c|c|}
\hline & $\begin{array}{c}(1) \\
\text { All injuries }\end{array}$ & $\begin{array}{c}(2) \\
\text { injury incidence rate } \\
\text { (All injuries) }\end{array}$ & $\begin{array}{c}(3) \\
\text { IC injuries }\end{array}$ & $\begin{array}{c}(4) \\
\text { injury incidence rate } \\
\text { (IC injuries) }\end{array}$ & $\begin{array}{c}(5) \\
\text { NIC injuries }\end{array}$ & $\begin{array}{c}(6) \\
\text { injury incidence rate } \\
\text { (NIC injuries) }\end{array}$ \\
\hline$\psi_{1}$ & $\begin{array}{l}-0.0481^{*} \\
(0.0256)\end{array}$ & $\begin{array}{l}-0.1493^{*} \\
(0.0873)\end{array}$ & $\begin{array}{c}-0.0210^{* *} \\
(0.0100)\end{array}$ & $\begin{array}{c}0.0264^{* *} \\
(0.0121)\end{array}$ & $\begin{array}{l}-0.0271 \\
(0.0240)\end{array}$ & $\begin{array}{c}-0.1757^{* *} \\
(0.0776)\end{array}$ \\
\hline$\psi_{2}$ & $\begin{array}{c}-0.0722^{* * *} \\
(0.0271)\end{array}$ & $\begin{array}{c}-0.4190^{* *} \\
(0.1721)\end{array}$ & $\begin{array}{l}-0.0174 \\
(0.0108)\end{array}$ & $\begin{array}{c}0.0217 \\
(0.0218)\end{array}$ & $\begin{array}{c}-0.0548^{* *} \\
(0.0242)\end{array}$ & $\begin{array}{c}-0.4406^{* * *} \\
(0.1540)\end{array}$ \\
\hline$\psi_{3}$ & $\begin{array}{c}-0.1112^{* * *} \\
(0.0397)\end{array}$ & $\begin{array}{c}-0.8575^{* * *} \\
(0.2470)\end{array}$ & $\begin{array}{l}-0.0219 \\
(0.0133)\end{array}$ & $\begin{array}{l}-0.0210 \\
(0.0311)\end{array}$ & $\begin{array}{c}-0.0893^{* *} \\
(0.0352)\end{array}$ & $\begin{array}{c}-0.8366^{* * *} \\
(0.2213)\end{array}$ \\
\hline$\psi_{4}$ & $\begin{array}{c}-0.1682^{* * *} \\
(0.0459)\end{array}$ & $\begin{array}{c}-1.2912^{* * *} \\
(0.3263)\end{array}$ & $\begin{array}{c}-0.0491^{* * *} \\
(0.0151)\end{array}$ & $\begin{array}{l}-0.0667^{*} \\
(0.0402)\end{array}$ & $\begin{array}{c}-0.1191^{* * *} \\
(0.0411)\end{array}$ & $\begin{array}{c}-1.2246^{* * *} \\
(0.2928)\end{array}$ \\
\hline$\psi_{5}$ & $\begin{array}{c}-0.1808^{* * *} \\
(0.0540)\end{array}$ & $\begin{array}{c}-1.6352^{* * * *} \\
(0.4126)\end{array}$ & $\begin{array}{c}-0.0507^{* * *} \\
(0.0180)\end{array}$ & $\begin{array}{c}-0.1018^{* *} \\
(0.0508)\end{array}$ & $\begin{array}{c}-0.1301^{* * *} \\
(0.0474)\end{array}$ & $\begin{array}{c}-1.5334^{* * *} \\
(0.3701)\end{array}$ \\
\hline$\psi_{6}$ & $\begin{array}{c}-0.1938^{* * *} \\
(0.0605)\end{array}$ & $\begin{array}{c}-1.9416^{* * *} \\
(0.4785)\end{array}$ & $\begin{array}{c}-0.0613^{* * *} \\
(0.0207)\end{array}$ & $\begin{array}{c}-0.1370^{* *} \\
(0.0588)\end{array}$ & $\begin{array}{c}-0.1325^{* *} \\
(0.0522)\end{array}$ & $\begin{array}{c}-1.8046^{* * *} \\
(0.4293)\end{array}$ \\
\hline$\psi_{7}$ & $\begin{array}{c}-0.1996^{* * *} \\
(0.0728)\end{array}$ & $\begin{array}{c}-2.0381^{* * * *} \\
(0.5532)\end{array}$ & $\begin{array}{c}-0.0661^{* * * *} \\
(0.0230)\end{array}$ & $\begin{array}{c}-0.1525^{* *} \\
(0.0695)\end{array}$ & $\begin{array}{c}-0.1335^{* *} \\
(0.0645)\end{array}$ & $\begin{array}{c}-1.8855^{* * *} \\
(0.4947)\end{array}$ \\
\hline$\psi_{8}$ & $\begin{array}{c}-0.2434^{* * *} \\
(0.0799)\end{array}$ & $\begin{array}{c}-2.2935^{* * *} \\
(0.6209)\end{array}$ & $\begin{array}{c}-0.0721^{* * *} \\
(0.0265)\end{array}$ & $\begin{array}{c}-0.1834^{* *} \\
(0.0805)\end{array}$ & $\begin{array}{c}-0.1713^{* *} \\
(0.0699)\end{array}$ & $\begin{array}{c}-2.1101^{* * *} \\
(0.5544)\end{array}$ \\
\hline$\psi_{9}$ & $\begin{array}{c}-0.2514^{* * *} \\
(0.0906)\end{array}$ & $\begin{array}{c}-2.7056^{* * *} \\
(0.7722)\end{array}$ & $\begin{array}{c}-0.0857^{* * *} \\
(0.0253)\end{array}$ & $\begin{array}{c}-0.2239 * * \\
(0.0933)\end{array}$ & $\begin{array}{c}-0.1657^{* *} \\
(0.0821)\end{array}$ & $\begin{array}{c}-2.4817^{* * * *} \\
(0.6907)\end{array}$ \\
\hline$\beta_{0}$ & $\begin{array}{c}0.0112^{* * * *} \\
(0.0032)\end{array}$ & $\begin{array}{c}0.1119^{* * *} \\
(0.0251)\end{array}$ & $\begin{array}{c}0.0047^{* * * *} \\
(0.0016)\end{array}$ & $\begin{array}{c}0.0124^{* * *} \\
(0.0033)\end{array}$ & $\begin{array}{l}0.0065^{*} \\
(0.0034)\end{array}$ & $\begin{array}{c}0.0996^{* * *} \\
(0.0225)\end{array}$ \\
\hline$\beta_{1}$ & $\begin{array}{c}0.0123^{* * *} \\
(0.0029)\end{array}$ & $\begin{array}{c}0.1215^{* * *} \\
(0.0250)\end{array}$ & $\begin{array}{c}0.0048^{* * * *} \\
(0.0014)\end{array}$ & $\begin{array}{c}0.0113^{* * *} \\
(0.0034)\end{array}$ & $\begin{array}{l}0.0075^{* *} \\
(0.0033)\end{array}$ & $\begin{array}{c}0.1102^{* * *} \\
(0.0223)\end{array}$ \\
\hline$\beta_{2}$ & $\begin{array}{c}0.0120^{* * *} \\
(0.0027)\end{array}$ & $\begin{array}{c}0.1326^{* * *} \\
(0.0254)\end{array}$ & $\begin{array}{c}0.0035^{* * * *} \\
(0.0013)\end{array}$ & $\begin{array}{c}0.0115^{* * *} \\
(0.0035)\end{array}$ & $\begin{array}{c}0.0085^{* * *} \\
(0.0029)\end{array}$ & $\begin{array}{c}0.1211^{* * *} \\
(0.0225)\end{array}$ \\
\hline$\beta_{3}$ & $\begin{array}{c}0.0154^{* * *} \\
(0.0029)\end{array}$ & $\begin{array}{c}0.1524^{* * *} \\
(0.0263)\end{array}$ & $\begin{array}{l}0.0034^{* *} \\
(0.0014)\end{array}$ & $\begin{array}{c}0.0139^{* * *} \\
(0.0035)\end{array}$ & $\begin{array}{c}0.0121^{* * *} \\
(0.0031)\end{array}$ & $\begin{array}{c}0.1386^{* * * *} \\
(0.0233)\end{array}$ \\
\hline$\beta_{4}$ & $\begin{array}{c}0.0186^{* * *} \\
(0.0031)\end{array}$ & $\begin{array}{c}0.1745^{* * *} \\
(0.0273)\end{array}$ & $\begin{array}{c}0.0048^{* * * *} \\
(0.0014)\end{array}$ & $\begin{array}{c}0.0164^{* * *} \\
(0.0036)\end{array}$ & $\begin{array}{c}0.0138^{* * *} \\
(0.0034)\end{array}$ & $\begin{array}{c}0.1580^{* * *} \\
(0.0243)\end{array}$ \\
\hline$\beta_{5}$ & $\begin{array}{c}0.0214^{* * *} \\
(0.0034)\end{array}$ & $\begin{array}{c}0.1919^{* * *} \\
(0.0295)\end{array}$ & $\begin{array}{c}0.0044^{* * * *} \\
(0.0014)\end{array}$ & $\begin{array}{c}0.0185^{* * *} \\
(0.0038)\end{array}$ & $\begin{array}{c}0.0170^{* * *} \\
(0.0036)\end{array}$ & $\begin{array}{c}0.1733^{* * *} \\
(0.0264)\end{array}$ \\
\hline$\beta_{6}$ & $\begin{array}{c}0.0224^{* * *} \\
(0.0035)\end{array}$ & $\begin{array}{c}0.2032^{* * *} \\
(0.0290)\end{array}$ & $\begin{array}{c}0.0048^{* * * *} \\
(0.0016)\end{array}$ & $\begin{array}{c}0.0198^{* * *} \\
(0.0039)\end{array}$ & $\begin{array}{c}0.0176^{* * *} \\
(0.0035)\end{array}$ & $\begin{array}{c}0.1834^{* * *} \\
(0.0259)\end{array}$ \\
\hline$\beta_{7}$ & $\begin{array}{c}0.0193^{* * *} \\
(0.0040)\end{array}$ & $\begin{array}{c}0.1980^{* * *} \\
(0.0298)\end{array}$ & $\begin{array}{c}0.0042^{* * * *} \\
(0.0015)\end{array}$ & $\begin{array}{c}0.0199^{* * *} \\
(0.0042)\end{array}$ & $\begin{array}{c}0.0151^{* * *} \\
(0.0040)\end{array}$ & $\begin{array}{c}0.1781^{* * *} \\
(0.0263)\end{array}$ \\
\hline$\beta_{8}$ & $\begin{array}{c}0.0233^{* * *} \\
(0.0034)\end{array}$ & $\begin{array}{c}0.1992^{* * *} \\
(0.0316)\end{array}$ & $\begin{array}{c}0.0045^{* * * *} \\
(0.0016)\end{array}$ & $\begin{array}{c}0.0198^{* * *} \\
(0.0043)\end{array}$ & $\begin{array}{c}0.0188^{* * *} \\
(0.0036)\end{array}$ & $\begin{array}{c}0.1794^{* * *} \\
(0.0281)\end{array}$ \\
\hline$\beta_{9}$ & $\begin{array}{c}0.0241^{* * *} \\
(0.0058)\end{array}$ & $\begin{array}{c}0.2300^{* * *} \\
(0.0481)\end{array}$ & $\begin{array}{c}0.0052^{* * *} \\
(0.0019)\end{array}$ & $\begin{array}{c}0.0229^{* * *} \\
(0.0062)\end{array}$ & $\begin{array}{c}0.0189^{* * *} \\
(0.0055)\end{array}$ & $\begin{array}{c}0.2070^{* * *} \\
(0.0425)\end{array}$ \\
\hline$\phi$ & $\begin{array}{c}-0.0166^{* * *} \\
(0.0018)\end{array}$ & $\begin{array}{c}-0.2823^{* * *} \\
(0.0155)\end{array}$ & $\begin{array}{l}-0.0006 \\
(0.0004)\end{array}$ & $\begin{array}{c}-0.0044^{* * * *} \\
(0.0016)\end{array}$ & $\begin{array}{c}-0.0160^{* * *} \\
(0.0018)\end{array}$ & $\begin{array}{c}-0.2780^{* * * *} \\
(0.0141)\end{array}$ \\
\hline$N$ & 362682 & 349379 & 362682 & 349379 & 362682 & 349379 \\
\hline$R^{2}$ & 0.003 & 0.146 & 0.000 & 0.083 & 0.003 & 0.157 \\
\hline
\end{tabular}

Note: $* * *$ significant at $1 \%,{ }^{* *}$ significant at $5 \%,{ }^{*}$ significant at $10 \%$. Robust standard errors in parentheses are clustered by region of entry per year of entry. Regressions include dummies for year of entry, region of entry, region of birth and current year. See equation 1 for the interpretation of $\phi, \beta$ and $\psi$ coefficients. The dependent variables are the number of injuries per thousand of days worked. IC stands for immediate care, indicating injuries which require immediate cares. NIC stands for non-immediate care. 


\section{A.1 Structure of the dataset}

Table A3: Structure of the dataset

\begin{tabular}{ccccccccc}
\hline individuals & \multicolumn{2}{c}{ Working spell } & year & injury & t0 & t1 & $\begin{array}{c}\text { initial } \\
\text { unemployment }\end{array}$ & $\begin{array}{c}\text { current } \\
\text { unemployment }\end{array}$ \\
\hline & spell start & spell stop & & & & & {$[.$.} & {$[.]$.} \\
$8 .]$. & {$[.]$.} & {$[.]$.} & {$[.]$.} & {$[.]$.} & {$[.]$.} & {$[.]$.} & {$[]$.} & 5.8 \\
881 & 14137 & $\mathbf{1 4 2 4 4}$ & 1998 & 0 & 0 & 107 & 5.8 & 4.7 \\
881 & $\mathbf{1 4 2 4 4}$ & $\mathbf{1 4 6 0 9}$ & 1999 & 0 & 107 & 472 & 5.8 & 4.4 \\
881 & $\mathbf{1 4 6 0 9}$ & $\mathbf{1 4 9 7 5}$ & 2000 & 0 & 472 & 838 & 5.8 & 3.7 \\
881 & $\mathbf{1 4 9 7 5}$ & $\mathbf{1 5 3 4 0}$ & 2001 & 0 & 838 & 1203 & 5.8 & 3.6 \\
881 & $\mathbf{1 5 3 4 0}$ & $\mathbf{1 5 7 0 5}$ & 2002 & 0 & 1203 & 1568 & 5.8 & {$[.]$.} \\
{$[.]$.} & $\mathbf{1 5 7 0 5}$ & $\mathbf{1 6 0 7 0}$ & 2003 & 0 & 1568 & 1933 & 5.8 & 6.2 \\
1808 & {$[.]$.} & {$[.]$.} & {$[.]$.} & {$[.]$.} & {$[.]$.} & {$[.]$.} & {$[.]$.} & 5.9 \\
1808 & $\mathbf{1 3 5 1 4}$ & $\mathbf{1 3 5 1 4}$ & 1996 & 0 & 0 & 351 & 6.2 & 5.8 \\
1808 & $\mathbf{1 3 8 7 9}$ & 14106 & 1997 & 0 & 351 & 716 & 6.2 & 5 \\
1808 & 14167 & $\mathbf{1 4 2 4 4}$ & 1998 & 0 & 1004 & 1081 & 6.2 & 4.7 \\
1808 & $\mathbf{1 4 2 4 4}$ & 14593 & 1999 & 0 & 1081 & 1430 & 6.2 & 3.7 \\
1808 & 14868 & 14873 & 2000 & 1 & 1705 & 1710 & 6.2 & {$[.]$.} \\
{$[. .]$.} & {$[.]$.} & {$[.]$.} & {$[.]$.} & {$[.]$.} & {$[.]$.} & {$[.]$.} & {$[.]$.} & \\
\hline
\end{tabular}


Table A4: Loglikelihood contributions

\begin{tabular}{|c|c|c|c|c|c|c|c|}
\hline Individual & Record & Year & $\begin{array}{l}\text { Censoring } \\
\text { Indicator }\end{array}$ & $\begin{array}{l}\text { Survival } \\
\text { Time }\end{array}$ & $\begin{array}{l}\text { Entry } \\
\text { Time }\end{array}$ & $\begin{array}{l}\text { Time Var. } \\
\text { Covariates }\end{array}$ & $\begin{array}{l}\text { Contribution to the } \\
\text { log likelihood }\end{array}$ \\
\hline \multicolumn{8}{|c|}{ Multiple data records after episode splitting in year specific records and interval truncation } \\
\hline 3 & 1 & 1994 & 0 & $t_{1}$ & 0 & $u r_{1994}$ & $\log \left(S\left(t_{1}\right)\right)$ \\
\hline 3 & 2 & 1995 & 0 & $t_{3}$ & $t_{2}$ & $u r_{1995}$ & $\log \left(S\left(t_{3}\right) / S\left(t_{2}\right)\right)$ \\
\hline 3 & 3 & {$[.]$.} & {$[.]$.} & {$[.]$.} & {$[.]$.} & {$[.]$.} & {$[.]$.} \\
\hline 4 & 1 & 1994 & 0 & $t_{1}$ & 0 & $u r_{1994}$ & $\log \left(S\left(t_{1}\right)\right)$ \\
\hline 4 & 2 & 1995 & 1 & $t_{3}$ & $t_{2}$ & $u r_{1995}$ & $\log \left(f\left(t_{3}\right) / S\left(t_{2}\right)\right)$ \\
\hline \multicolumn{8}{|c|}{ Multiple data records after episode splitting in year specific records and no interval truncatio } \\
\hline 1 & 1 & 1994 & 0 & $t_{1}$ & 0 & $u r_{1994}$ & $\log \left(S\left(t_{1}\right)\right)$ \\
\hline 1 & 2 & 1995 & 0 & $t_{2}$ & $t_{1}$ & $u r_{1995}$ & $\log \left(S\left(t_{2}\right) / S\left(t_{1}\right)\right)$ \\
\hline 1 & 3 & {$[.]$.} & {$[.]$.} & {$[.]$.} & {$[.]$.} & {$[.]$.} & {$[.]$.} \\
\hline 2 & 1 & 1994 & 0 & $t_{1}$ & 0 & $u r_{1994}$ & $\log \left(S\left(t_{1}\right)\right)$ \\
\hline 2 & 2 & 1995 & 1 & $t_{2}$ & $t_{1}$ & $u r_{1995}$ & $\log \left(f\left(t_{2}\right) / S\left(t_{1}\right)\right)$ \\
\hline
\end{tabular}

\section{A.2 Log likelihood specification}

\section{A.2.1 Episode splitting and interval truncation}

In our preferred specification we use a loglogistic hazard function. As shown in Table A3 we have split the episodes in year-specific records to incorporate time-varying covariates. The contribution of each record to the loglikelihood function for individual $i$ is as follows:

$$
\log L_{i}=c_{i} \log \left[\theta\left(T_{i}\right)\right]+\log \left[S\left(T_{i}\right)\right]
$$

where $c_{i}=1$ if the spell ends with an injury and 0 if the individual $i$ is censored. $\theta\left(T_{i}\right)$ is the hazard rate and is equal to $f\left(T_{i}\right) / S\left(T_{i}\right)$. Given the structure of our dataset we consider the individuals to be at risk of injury only during episodes of employment. Since some individuals experience periods of unemployment, we have interval truncation. More precisely, we observe each worker at the time of first entry; thus, we know the spell start date and the time at which the individual is first at risk. However, if a spell of unemployment occurs, we observe subsequent year specific records with delayed entry. For example, if individual $i$ is employed for $t_{1}$ days in his first job but experiences unemployment between $t_{1}$ and $t_{2}$, the hazard function and survivor function computed at the first year-specific record at reemployment should be conditional on the survival function computed at time $t_{2}$.

Table A4 summarizes the contributions to the log-likelihood of each year-specific record for individuals, censored and not censored, with and without interval truncations. 
Table A5: The effect of initial and contemporaneous labor market conditions on weekly wage and individual level injuries: Excluding entrants in a region different from the region of birth

\begin{tabular}{|c|c|c|c|c|}
\hline & (1) & (2) & (3) & (4) \\
\hline & ln(wage) & All injuries & IC injuries & NIC injuries \\
\hline \multirow[t]{2}{*}{$\psi_{1}$} & $0.1136^{* * *}$ & $-0.0744^{* * *}$ & $-0.0270^{* *}$ & $-0.0474^{*}$ \\
\hline & $(0.0084)$ & $(0.0268)$ & $(0.0111)$ & $(0.0242)$ \\
\hline \multirow[t]{2}{*}{$\psi_{2}$} & $0.2330^{* * *}$ & $-0.0830^{* * *}$ & $-0.0230^{* *}$ & $-0.0600^{* *}$ \\
\hline & $(0.0133)$ & $(0.0290)$ & $(0.0114)$ & $(0.0255)$ \\
\hline \multirow[t]{2}{*}{$\psi_{3}$} & $0.3348^{* * *}$ & $-0.1226^{* * *}$ & $-0.0288^{* *}$ & $-0.0939^{* * *}$ \\
\hline & $(0.0191)$ & $(0.0401)$ & $(0.0144)$ & $(0.0345)$ \\
\hline \multirow[t]{2}{*}{$\psi_{4}$} & $0.4226^{* * *}$ & $-0.1641^{* * *}$ & $-0.0560^{* * *}$ & $-0.1081^{* * *}$ \\
\hline & $(0.0249)$ & $(0.0437)$ & $(0.0166)$ & $(0.0389)$ \\
\hline \multirow[t]{2}{*}{$\psi_{5}$} & $0.4897^{* * *}$ & $-0.1725^{* * *}$ & $-0.0566^{* * *}$ & $-0.1159^{* *}$ \\
\hline & $(0.0304)$ & $(0.0545)$ & $(0.0193)$ & $(0.0474)$ \\
\hline \multirow[t]{2}{*}{$\psi_{6}$} & $0.5585^{* * *}$ & $-0.1871^{* * *}$ & $-0.0672^{* * *}$ & $-0.1198^{* *}$ \\
\hline & $(0.0373)$ & $(0.0621)$ & $(0.0227)$ & $(0.0541)$ \\
\hline \multirow{2}{*}{$\psi_{7}$} & $0.6152^{* * *}$ & $-0.1830^{* *}$ & $-0.0704^{* * *}$ & $-0.1126^{*}$ \\
\hline & $(0.0422)$ & $(0.0723)$ & $(0.0250)$ & $(0.0629)$ \\
\hline \multirow[t]{2}{*}{$\psi_{8}$} & $0.6716^{* * *}$ & $-0.2424^{* * *}$ & $-0.0779^{* * *}$ & $-0.1646^{* *}$ \\
\hline & $(0.0494)$ & $(0.0810)$ & $(0.0282)$ & $(0.0702)$ \\
\hline \multirow[t]{2}{*}{$\psi_{9}$} & $0.7175^{* * *}$ & $-0.2585^{* * *}$ & $-0.0959^{* * *}$ & $-0.1626^{*}$ \\
\hline & $(0.0573)$ & $(0.0932)$ & $(0.0271)$ & $(0.0834)$ \\
\hline \multirow[t]{2}{*}{$\beta_{0}$} & $0.0174^{* * *}$ & $0.0120^{* * *}$ & $0.0042^{* *}$ & $0.0077^{* *}$ \\
\hline & $(0.0019)$ & $(0.0034)$ & $(0.0016)$ & $(0.0038)$ \\
\hline \multirow[t]{2}{*}{$\beta_{1}$} & $0.0160^{* * *}$ & $0.0146^{* * *}$ & $0.0047^{* * *}$ & $0.0099^{* * *}$ \\
\hline & $(0.0019)$ & $(0.0033)$ & $(0.0015)$ & $(0.0037)$ \\
\hline \multirow[t]{2}{*}{$\beta_{2}$} & $0.0144^{* * *}$ & $0.0138^{* * *}$ & $0.0034^{* *}$ & $0.0104^{* * *}$ \\
\hline & $(0.0020)$ & $(0.0029)$ & $(0.0014)$ & $(0.0032)$ \\
\hline \multirow[t]{2}{*}{$\beta_{3}$} & $0.0122^{* * *}$ & $0.0175^{* * *}$ & $0.0033^{* *}$ & $0.0143^{* * *}$ \\
\hline & $(0.0020)$ & $(0.0030)$ & $(0.0014)$ & $(0.0033)$ \\
\hline \multirow[t]{2}{*}{$\beta_{4}$} & $0.0102^{* * *}$ & $0.0190^{* * *}$ & $0.0047^{* * *}$ & $0.0142^{* * *}$ \\
\hline & $(0.0022)$ & $(0.0033)$ & $(0.0014)$ & $(0.0037)$ \\
\hline \multirow{2}{*}{$\beta_{5}$} & $0.0088^{* * *}$ & $0.0227^{* * *}$ & $0.0043^{* * *}$ & $0.0185^{* * *}$ \\
\hline & $(0.0022)$ & $(0.0037)$ & $(0.0015)$ & $(0.0040)$ \\
\hline \multirow[t]{2}{*}{$\beta_{6}$} & $0.0063^{* *}$ & $0.0237^{* * *}$ & $0.0047^{* * *}$ & $0.0190^{* * *}$ \\
\hline & $(0.0025)$ & $(0.0039)$ & $(0.0016)$ & $(0.0040)$ \\
\hline \multirow[t]{2}{*}{$\beta_{7}$} & $0.0049^{*}$ & $0.0203^{* * *}$ & $0.0039^{* *}$ & $0.0164^{* * *}$ \\
\hline & $(0.0027)$ & $(0.0042)$ & $(0.0015)$ & $(0.0042)$ \\
\hline \multirow[t]{2}{*}{$\beta_{8}$} & 0.0037 & $0.0253^{* * *}$ & $0.0043^{* *}$ & $0.0210^{* * *}$ \\
\hline & $(0.0027)$ & $(0.0037)$ & $(0.0017)$ & $(0.0040)$ \\
\hline \multirow[t]{2}{*}{$\beta_{9}$} & 0.0030 & $0.0264^{* * *}$ & $0.0053^{* * *}$ & $0.0211^{* * *}$ \\
\hline & $(0.0037)$ & $(0.0065)$ & $(0.0019)$ & $(0.0063)$ \\
\hline \multirow[t]{2}{*}{$\phi$} & $-0.0077^{* * *}$ & $-0.0194^{* * *}$ & -0.0006 & $-0.0188^{* * *}$ \\
\hline & $(0.0006)$ & $(0.0025)$ & $(0.0006)$ & $(0.0024)$ \\
\hline$N$ & 313697 & 313697 & 313697 & 313697 \\
\hline$R^{2}$ & 0.172 & 0.002 & 0.000 & 0.002 \\
\hline
\end{tabular}

Robust standard errors in parentheses are clustered by region of entry per year of entry. Regressions include dummies for year of entry, region of entry, region of birth and current year. See equation 1 for the interpretation of $\phi, \beta$ and $\psi$ coefficients. ${ }^{* * *}$ significant at $1 \%,{ }^{* *}$ significant at $5 \%,{ }^{*}$ significant at $10 \%$. 
Table A6: The effect of initial and contemporaneous labor market conditions on weekly wage and individual level injuries using as additional controls all the possible interactions between region of entry dummies and region of birth dummies.

\begin{tabular}{|c|c|c|c|c|}
\hline & (1) & (2) & (3) & (4) \\
\hline & $\ln$ (wage) & All injuries & IC injuries & NIC injuries \\
\hline \multirow[t]{2}{*}{$\psi_{1}$} & $0.1070^{* * *}$ & $-0.0477^{*}$ & $-0.0209^{* *}$ & -0.0268 \\
\hline & $(0.0077)$ & $(0.0256)$ & $(0.0100)$ & $(0.0240)$ \\
\hline \multirow[t]{2}{*}{$\psi_{2}$} & $0.2229^{* * *}$ & $-0.0709^{* * *}$ & -0.0171 & $-0.0539^{* *}$ \\
\hline & $(0.0128)$ & $(0.0271)$ & $(0.0108)$ & $(0.0241)$ \\
\hline \multirow[t]{2}{*}{$\psi_{3}$} & $0.3182^{* * *}$ & $-0.1084^{* * *}$ & -0.0215 & $-0.0869^{* *}$ \\
\hline & $(0.0180)$ & $(0.0403)$ & $(0.0134)$ & $(0.0355)$ \\
\hline \multirow[t]{2}{*}{$\psi_{4}$} & $0.4042^{* * *}$ & $-0.1646^{* * *}$ & $-0.0484^{* * *}$ & $-0.1162^{* * *}$ \\
\hline & $(0.0238)$ & $(0.0462)$ & $(0.0152)$ & $(0.0413)$ \\
\hline \multirow[t]{2}{*}{$\psi_{5}$} & $0.4720^{* * *}$ & $-0.1754^{* * *}$ & $-0.0497^{* * *}$ & $-0.1257^{* * *}$ \\
\hline & $(0.0291)$ & $(0.0548)$ & $(0.0182)$ & $(0.0480)$ \\
\hline \multirow[t]{2}{*}{$\psi_{6}$} & $0.5396^{* * *}$ & $-0.1873^{* * *}$ & $-0.0600^{* * *}$ & $-0.1273^{* *}$ \\
\hline & $(0.0358)$ & $(0.0608)$ & $(0.0211)$ & $(0.0521)$ \\
\hline \multirow[t]{2}{*}{$\psi_{7}$} & $0.5962^{* * *}$ & $-0.1927^{* * *}$ & $-0.0645^{* * *}$ & $-0.1282^{* *}$ \\
\hline & $(0.0398)$ & $(0.0729)$ & $(0.0234)$ & $(0.0642)$ \\
\hline \multirow[t]{2}{*}{$\psi_{8}$} & $0.6487^{* * *}$ & $-0.2353^{* * *}$ & $-0.0702^{* * *}$ & $-0.1651^{* *}$ \\
\hline & $(0.0468)$ & $(0.0802)$ & $(0.0269)$ & $(0.0698)$ \\
\hline \multirow[t]{2}{*}{$\psi_{9}$} & $0.7017^{* * *}$ & $-0.2425^{* * *}$ & $-0.0834^{* * *}$ & $-0.1591^{*}$ \\
\hline & $(0.0557)$ & $(0.0900)$ & $(0.0258)$ & $(0.0812)$ \\
\hline \multirow[t]{2}{*}{$\beta_{0}$} & $0.0154^{* * *}$ & $0.0112^{* * *}$ & $0.0046^{* * *}$ & $0.0066^{*}$ \\
\hline & $(0.0018)$ & $(0.0031)$ & $(0.0016)$ & $(0.0034)$ \\
\hline \multirow[t]{2}{*}{$\beta_{1}$} & $0.0144^{* * *}$ & $0.0124^{* * *}$ & $0.0047^{* * *}$ & $0.0077^{* *}$ \\
\hline & $(0.0018)$ & $(0.0030)$ & $(0.0014)$ & $(0.0034)$ \\
\hline \multirow[t]{2}{*}{$\beta_{2}$} & $0.0129^{* * *}$ & $0.0120^{* * *}$ & $0.0034^{* * *}$ & $0.0086^{* * *}$ \\
\hline & $(0.0019)$ & $(0.0027)$ & $(0.0013)$ & $(0.0030)$ \\
\hline \multirow[t]{2}{*}{$\beta_{3}$} & $0.0112^{* * *}$ & $0.0155^{* * *}$ & $0.0033^{* *}$ & $0.0122^{* * *}$ \\
\hline & $(0.0019)$ & $(0.0029)$ & $(0.0014)$ & $(0.0031)$ \\
\hline \multirow[t]{2}{*}{$\beta_{4}$} & $0.0093^{* * *}$ & $0.0187^{* * *}$ & $0.0048^{* * *}$ & $0.0139^{* * *}$ \\
\hline & $(0.0021)$ & $(0.0031)$ & $(0.0014)$ & $(0.0035)$ \\
\hline \multirow[t]{2}{*}{$\beta_{5}$} & $0.0078^{* * *}$ & $0.0214^{* * *}$ & $0.0043^{* * *}$ & $0.0170^{* * *}$ \\
\hline & $(0.0021)$ & $(0.0034)$ & $(0.0014)$ & $(0.0037)$ \\
\hline \multirow[t]{2}{*}{$\beta_{6}$} & $0.0056^{* *}$ & $0.0224^{* * *}$ & $0.0048^{* * *}$ & $0.0177^{* * *}$ \\
\hline & $(0.0024)$ & $(0.0035)$ & $(0.0016)$ & $(0.0036)$ \\
\hline \multirow[t]{2}{*}{$\beta_{7}$} & $0.0042^{*}$ & $0.0194^{* * *}$ & $0.0041^{* * *}$ & $0.0153^{* * *}$ \\
\hline & $(0.0024)$ & $(0.0040)$ & $(0.0015)$ & $(0.0040)$ \\
\hline \multirow[t]{2}{*}{$\beta_{8}$} & 0.0034 & $0.0234^{* * *}$ & $0.0044^{* * *}$ & $0.0190^{* * *}$ \\
\hline & $(0.0026)$ & $(0.0034)$ & $(0.0016)$ & $(0.0037)$ \\
\hline \multirow[t]{2}{*}{$\beta_{9}$} & 0.0022 & $0.0243^{* * *}$ & $0.0051^{* * *}$ & $0.0192^{* * *}$ \\
\hline & $(0.0034)$ & $(0.0058)$ & $(0.0018)$ & $(0.0056)$ \\
\hline \multirow[t]{2}{*}{$\phi$} & $-0.0078^{* * *}$ & $-0.0163^{* * *}$ & -0.0006 & $-0.0157^{* * *}$ \\
\hline & $(0.0005)$ & $(0.0018)$ & $(0.0004)$ & $(0.0018)$ \\
\hline$N$ & 362682 & 362682 & 362682 & 362682 \\
\hline$R^{2}$ & 0.167 & 0.004 & 0.001 & 0.004 \\
\hline
\end{tabular}

Robust standard errors in parentheses are clustered by region of entry per year of entry. Regressions include dummies for year of entry, region of entry, region of birth, current year and all the possible interactions between region of entry dummies and region of birth dummies. See equation 1 for the interpretation of $\phi, \beta$ and $\psi$ coefficients. $* * *$ significant at $1 \%,{ }^{* *}$ significant at $5 \%,{ }^{*}$ significant at $10 \%$. 
Table A7: The effect of initial and contemporaneous labor market conditions on weekly wage and individual level injuries: Including only entrants born in the North-Center regions

\begin{tabular}{|c|c|c|c|c|}
\hline & (1) & (2) & (3) & (4) \\
\hline & ln(wage) & All injuries & IC injuries & NIC injuries \\
\hline \multirow[t]{2}{*}{$\psi_{1}$} & $0.0997^{* * *}$ & -0.0408 & -0.0146 & -0.0262 \\
\hline & $(0.0086)$ & $(0.0408)$ & $(0.0128)$ & $(0.0380)$ \\
\hline \multirow[t]{2}{*}{$\psi_{2}$} & $0.2227^{* * *}$ & $-0.0708^{*}$ & $-0.0263^{* *}$ & -0.0444 \\
\hline & $(0.0141)$ & $(0.0419)$ & $(0.0131)$ & $(0.0396)$ \\
\hline \multirow[t]{2}{*}{$\psi_{3}$} & $0.3216^{* * *}$ & $-0.1358^{* * *}$ & $-0.0304^{*}$ & $-0.1054^{* *}$ \\
\hline & $(0.0186)$ & $(0.0519)$ & $(0.0160)$ & $(0.0496)$ \\
\hline \multirow[t]{2}{*}{$\psi_{4}$} & $0.4125^{* * *}$ & $-0.2085^{* * *}$ & $-0.0597^{* * *}$ & $-0.1489^{* * *}$ \\
\hline & $(0.0242)$ & $(0.0580)$ & $(0.0167)$ & $(0.0556)$ \\
\hline \multirow[t]{2}{*}{$\psi_{5}$} & $0.4839^{* * *}$ & $-0.2082^{* * *}$ & $-0.0735^{* * *}$ & $-0.1347^{* *}$ \\
\hline & $(0.0292)$ & $(0.0635)$ & $(0.0208)$ & $(0.0582)$ \\
\hline \multirow[t]{2}{*}{$\psi_{6}$} & $0.5461^{* * *}$ & $-0.2874^{* * *}$ & $-0.0801^{* * *}$ & $-0.2073^{* *}$ \\
\hline & $(0.0343)$ & $(0.0837)$ & $(0.0238)$ & $(0.0809)$ \\
\hline \multirow{2}{*}{$\psi_{7}$} & $0.6137^{* * *}$ & $-0.2368^{* * *}$ & $-0.0807^{* * *}$ & $-0.1561^{*}$ \\
\hline & $(0.0394)$ & $(0.0887)$ & $(0.0256)$ & $(0.0853)$ \\
\hline \multirow[t]{2}{*}{$\psi_{8}$} & $0.6579^{* * *}$ & $-0.3584^{* * *}$ & $-0.1169^{* * *}$ & $-0.2415^{* *}$ \\
\hline & $(0.0475)$ & $(0.1029)$ & $(0.0298)$ & $(0.0956)$ \\
\hline \multirow[t]{2}{*}{$\psi_{9}$} & $0.7054^{* * *}$ & $-0.2806^{* *}$ & $-0.1173^{* * *}$ & -0.1634 \\
\hline & $(0.0585)$ & (0.1199) & $(0.0306)$ & $(0.1147)$ \\
\hline \multirow[t]{2}{*}{$\beta_{0}$} & $0.0101^{* * *}$ & -0.0006 & $0.0052^{* *}$ & -0.0058 \\
\hline & $(0.0031)$ & (0.0109) & $(0.0023)$ & $(0.0103)$ \\
\hline \multirow[t]{2}{*}{$\beta_{1}$} & $0.0104^{* * *}$ & -0.0038 & $0.0033^{* *}$ & -0.0071 \\
\hline & $(0.0032)$ & $(0.0091)$ & $(0.0016)$ & $(0.0087)$ \\
\hline \multirow[t]{2}{*}{$\beta_{2}$} & $0.0079^{* *}$ & -0.0016 & $0.0041^{* *}$ & -0.0057 \\
\hline & $(0.0031)$ & $(0.0097)$ & $(0.0018)$ & $(0.0092)$ \\
\hline \multirow[t]{2}{*}{$\beta_{3}$} & $0.0056^{*}$ & 0.0051 & $0.0031^{*}$ & 0.0020 \\
\hline & $(0.0030)$ & $(0.0104)$ & $(0.0017)$ & $(0.0097)$ \\
\hline \multirow[t]{2}{*}{$\beta_{4}$} & 0.0028 & 0.0096 & $0.0044^{* *}$ & 0.0052 \\
\hline & $(0.0030)$ & $(0.0097)$ & $(0.0018)$ & $(0.0092)$ \\
\hline \multirow{2}{*}{$\beta_{5}$} & 0.0007 & 0.0104 & $0.0052^{* * *}$ & 0.0052 \\
\hline & $(0.0031)$ & $(0.0098)$ & $(0.0020)$ & $(0.0094)$ \\
\hline \multirow[t]{2}{*}{$\beta_{6}$} & -0.0007 & $0.0210^{*}$ & $0.0044^{* *}$ & 0.0166 \\
\hline & $(0.0032)$ & $(0.0122)$ & $(0.0022)$ & $(0.0116)$ \\
\hline \multirow[t]{2}{*}{$\beta_{7}$} & -0.0037 & 0.0092 & 0.0030 & 0.0062 \\
\hline & $(0.0034)$ & $(0.0113)$ & $(0.0020)$ & $(0.0108)$ \\
\hline \multirow[t]{2}{*}{$\beta_{8}$} & -0.0033 & $0.0226^{*}$ & $0.0070^{* * *}$ & 0.0156 \\
\hline & $(0.0037)$ & $(0.0119)$ & $(0.0026)$ & $(0.0113)$ \\
\hline \multirow[t]{2}{*}{$\beta_{9}$} & -0.0042 & 0.0105 & 0.0052 & 0.0053 \\
\hline & $(0.0048)$ & $(0.0144)$ & $(0.0032)$ & $(0.0132)$ \\
\hline \multirow[t]{2}{*}{$\phi$} & $-0.0055^{* * *}$ & $-0.0122^{* * *}$ & -0.0001 & $-0.0121^{* * *}$ \\
\hline & $(0.0017)$ & $(0.0038)$ & $(0.0007)$ & $(0.0036)$ \\
\hline$N$ & 251783 & 251783 & 251783 & 251783 \\
\hline$R^{2}$ & 0.193 & 0.002 & 0.000 & 0.002 \\
\hline
\end{tabular}

Robust standard errors in parentheses are clustered by region of entry per year of entry. Regressions include dummies for year of entry, region of entry, region of birth and current year. See equation 1 for the interpretation of $\phi, \beta$ and $\psi$ coefficients. ${ }^{* * *}$ significant at $1 \%,{ }^{* *}$ significant at $5 \%,{ }^{*}$ significant at $10 \%$. 
Table A8: The effect of initial and contemporaneous labor market conditions on weekly wage and individual level injuries: Including only entrants born in the South and Islands

\begin{tabular}{|c|c|c|c|c|}
\hline & (1) & $(2)$ & $(3)$ & (4) \\
\hline & $\ln$ (wage) & All injuries & IC injuries & NIC injuries \\
\hline \multirow[t]{2}{*}{$\psi_{1}$} & $0.0801^{* * *}$ & 0.0759 & 0.0119 & 0.0639 \\
\hline & $(0.0149)$ & $(0.0627)$ & $(0.0171)$ & $(0.0637)$ \\
\hline \multirow[t]{2}{*}{$\psi_{2}$} & $0.1568^{* * *}$ & -0.0323 & 0.0194 & -0.0517 \\
\hline & $(0.0243)$ & $(0.0634)$ & $(0.0209)$ & $(0.0604)$ \\
\hline \multirow{2}{*}{$\psi_{3}$} & $0.2192^{* * *}$ & -0.0552 & 0.0352 & -0.0903 \\
\hline & $(0.0343)$ & $(0.0844)$ & $(0.0256)$ & $(0.0809)$ \\
\hline \multirow[t]{2}{*}{$\psi_{4}$} & $0.2789^{* * *}$ & -0.0528 & 0.0173 & -0.0701 \\
\hline & $(0.0432)$ & $(0.0910)$ & $(0.0288)$ & $(0.0870)$ \\
\hline \multirow[t]{2}{*}{$\psi_{5}$} & $0.3338^{* * *}$ & -0.0470 & 0.0283 & -0.0753 \\
\hline & $(0.0530)$ & $(0.1172)$ & $(0.0319)$ & $(0.1160)$ \\
\hline \multirow[t]{2}{*}{$\psi_{6}$} & $0.3732^{* * *}$ & -0.0502 & 0.0397 & -0.0899 \\
\hline & $(0.0656)$ & $(0.1272)$ & $(0.0353)$ & $(0.1223)$ \\
\hline \multirow[t]{2}{*}{$\psi_{7}$} & $0.3998^{* * *}$ & -0.0610 & 0.0220 & -0.0830 \\
\hline & $(0.0745)$ & $(0.1393)$ & $(0.0416)$ & $(0.1303)$ \\
\hline \multirow[t]{2}{*}{$\psi_{8}$} & $0.4202^{* * *}$ & -0.0438 & 0.0278 & -0.0716 \\
\hline & $(0.0838)$ & $(0.1630)$ & $(0.0473)$ & $(0.1537)$ \\
\hline \multirow[t]{2}{*}{$\psi_{9}$} & $0.4776^{* * *}$ & -0.0133 & 0.0632 & -0.0765 \\
\hline & $(0.1090)$ & $(0.1993)$ & $(0.0488)$ & $(0.1955)$ \\
\hline \multirow[t]{2}{*}{$\beta_{0}$} & $0.0060^{* * *}$ & $0.0143^{* *}$ & $0.0062^{* * *}$ & 0.0082 \\
\hline & $(0.0018)$ & $(0.0057)$ & $(0.0023)$ & $(0.0057)$ \\
\hline \multirow[t]{2}{*}{$\beta_{1}$} & $0.0060^{* * *}$ & $0.0105^{*}$ & $0.0054^{* *}$ & 0.0051 \\
\hline & $(0.0017)$ & $(0.0054)$ & $(0.0023)$ & $(0.0053)$ \\
\hline \multirow[t]{2}{*}{$\beta_{2}$} & $0.0065^{* * *}$ & $0.0149^{* * *}$ & $0.0044^{* *}$ & $0.0105^{* *}$ \\
\hline & $(0.0018)$ & $(0.0055)$ & $(0.0022)$ & $(0.0052)$ \\
\hline \multirow[t]{2}{*}{$\beta_{3}$} & $0.0064^{* * *}$ & $0.0182^{* * *}$ & $0.0041^{*}$ & $0.0141^{* *}$ \\
\hline & $(0.0017)$ & $(0.0058)$ & $(0.0022)$ & $(0.0054)$ \\
\hline \multirow[t]{2}{*}{$\beta_{4}$} & $0.0058^{* * *}$ & $0.0189^{* * *}$ & $0.0058^{* *}$ & $0.0131^{* *}$ \\
\hline & $(0.0019)$ & $(0.0058)$ & $(0.0023)$ & $(0.0055)$ \\
\hline \multirow[t]{2}{*}{$\beta_{5}$} & $0.0049^{* *}$ & $0.0212^{* * *}$ & $0.0053^{* *}$ & $0.0159^{* * *}$ \\
\hline & $(0.0019)$ & $(0.0061)$ & $(0.0023)$ & $(0.0059)$ \\
\hline \multirow[t]{2}{*}{$\beta_{6}$} & $0.0038^{*}$ & $0.0213^{* * *}$ & $0.0054^{* *}$ & $0.0158^{* * *}$ \\
\hline & $(0.0020)$ & $(0.0062)$ & $(0.0026)$ & $(0.0056)$ \\
\hline \multirow[t]{2}{*}{$\beta_{7}$} & $0.0039^{*}$ & $0.0204^{* * *}$ & $0.0061^{* *}$ & $0.0143^{* *}$ \\
\hline & $(0.0021)$ & $(0.0062)$ & $(0.0024)$ & $(0.0057)$ \\
\hline \multirow[t]{2}{*}{$\beta_{8}$} & $0.0044^{* *}$ & $0.0216^{* * *}$ & $0.0063^{* *}$ & $0.0153^{* *}$ \\
\hline & $(0.0022)$ & $(0.0067)$ & $(0.0025)$ & $(0.0066)$ \\
\hline \multirow[t]{2}{*}{$\beta_{9}$} & 0.0029 & $0.0224^{* * *}$ & 0.0049 & $0.0175^{* *}$ \\
\hline & $(0.0024)$ & $(0.0085)$ & $(0.0034)$ & $(0.0078)$ \\
\hline \multirow[t]{2}{*}{$\phi$} & $-0.0073^{* * *}$ & $-0.0174^{* * *}$ & -0.0008 & $-0.0166^{* * *}$ \\
\hline & $(0.0005)$ & $(0.0021)$ & $(0.0005)$ & $(0.0020)$ \\
\hline$N$ & 110899 & 110899 & 110899 & 110899 \\
\hline$R^{2}$ & 0.095 & 0.005 & 0.001 & 0.005 \\
\hline
\end{tabular}

Robust standard errors in parentheses are clustered by region of entry per year of entry. Regressions include dummies for year of entry, region of entry, region of birth and current year. See equation 1 for the interpretation of $\phi, \beta$ and $\psi$ coefficients. ${ }^{* * *}$ significant at $1 \%,{ }^{*}$ significant at $5 \%,{ }^{*}$ significant at $10 \%$. 
Table A9: The effect of initial and contemporaneous labor market conditions on weekly wage and individual level injuries: Controlling for initial job and firm characteristics

\begin{tabular}{|c|c|c|c|c|}
\hline & (1) & $(2)$ & $(3)$ & (4) \\
\hline & $\ln$ (wage) & All injuries & $\mathrm{IC}$ injuries & NIC injuries \\
\hline \multirow[t]{2}{*}{$\psi_{1}$} & $0.1035^{* * *}$ & $-0.0563^{*}$ & $-0.0227^{* *}$ & -0.0337 \\
\hline & $(0.0111)$ & $(0.0297)$ & $(0.0091)$ & $(0.0282)$ \\
\hline \multirow[t]{2}{*}{$\psi_{2}$} & $0.2213^{* * *}$ & $-0.0955^{* *}$ & $-0.0188^{*}$ & $-0.0767^{*}$ \\
\hline & $(0.0210)$ & $(0.0407)$ & $(0.0107)$ & $(0.0396)$ \\
\hline \multirow[t]{2}{*}{$\psi_{3}$} & $0.3134^{* * *}$ & $-0.1348^{* *}$ & $-0.0236^{*}$ & $-0.1112^{* *}$ \\
\hline & $(0.0312)$ & $(0.0584)$ & $(0.0136)$ & $(0.0551)$ \\
\hline \multirow[t]{2}{*}{$\psi_{4}$} & $0.3998^{* * *}$ & $-0.2002^{* * *}$ & $-0.0530^{* * *}$ & $-0.1472^{* *}$ \\
\hline & $(0.0409)$ & $(0.0764)$ & $(0.0173)$ & $(0.0739)$ \\
\hline \multirow[t]{2}{*}{$\psi_{5}$} & $0.4658^{* * *}$ & $-0.2176^{* *}$ & $-0.0547^{* *}$ & $-0.1629^{*}$ \\
\hline & $(0.0513)$ & $(0.0910)$ & $(0.0210)$ & $(0.0876)$ \\
\hline \multirow[t]{2}{*}{$\psi_{6}$} & $0.5325^{* * *}$ & $-0.2358^{* *}$ & $-0.0667^{* *}$ & $-0.1692^{*}$ \\
\hline & $(0.0624)$ & $(0.1055)$ & $(0.0259)$ & $(0.1008)$ \\
\hline \multirow[t]{2}{*}{$\psi_{7}$} & $0.5891^{* * *}$ & $-0.2501^{* *}$ & $-0.0714^{* *}$ & -0.1787 \\
\hline & $(0.0704)$ & $(0.1260)$ & $(0.0293)$ & $(0.1227)$ \\
\hline \multirow[t]{2}{*}{$\psi_{8}$} & $0.6419^{* * *}$ & $-0.3017^{* *}$ & $-0.0786^{* *}$ & -0.2231 \\
\hline & $(0.0821)$ & $(0.1435)$ & $(0.0334)$ & $(0.1356)$ \\
\hline \multirow[t]{2}{*}{$\psi_{9}$} & $0.6931^{* * *}$ & $-0.3132^{* *}$ & $-0.0920^{* * *}$ & -0.2211 \\
\hline & $(0.0938)$ & $(0.1564)$ & $(0.0347)$ & $(0.1540)$ \\
\hline \multirow[t]{2}{*}{$\beta_{0}$} & $0.0141^{* * *}$ & $0.0067^{*}$ & $0.0045^{* * *}$ & 0.0022 \\
\hline & $(0.0017)$ & $(0.0034)$ & $(0.0017)$ & $(0.0036)$ \\
\hline \multirow[t]{2}{*}{$\beta_{1}$} & $0.0129^{* * *}$ & $0.0077^{* *}$ & $0.0045^{* * *}$ & 0.0032 \\
\hline & $(0.0017)$ & $(0.0031)$ & $(0.0015)$ & $(0.0034)$ \\
\hline \multirow[t]{2}{*}{$\beta_{2}$} & $0.0112^{* * *}$ & $0.0084^{* * *}$ & $0.0032^{* *}$ & $0.0053^{*}$ \\
\hline & $(0.0017)$ & $(0.0030)$ & $(0.0014)$ & $(0.0031)$ \\
\hline \multirow[t]{2}{*}{$\beta_{3}$} & $0.0097^{* * *}$ & $0.0115^{* * *}$ & $0.0030^{* *}$ & $0.0085^{* * *}$ \\
\hline & $(0.0018)$ & $(0.0031)$ & $(0.0015)$ & $(0.0032)$ \\
\hline \multirow[t]{2}{*}{$\beta_{4}$} & $0.0078^{* * *}$ & $0.0148^{* * *}$ & $0.0046^{* * *}$ & $0.0102^{* * *}$ \\
\hline & $(0.0019)$ & $(0.0034)$ & $(0.0014)$ & $(0.0035)$ \\
\hline \multirow[t]{2}{*}{$\beta_{5}$} & $0.0065^{* * *}$ & $0.0181^{* * *}$ & $0.0042^{* * *}$ & $0.0139^{* * *}$ \\
\hline & $(0.0019)$ & $(0.0037)$ & $(0.0015)$ & $(0.0038)$ \\
\hline \multirow[t]{2}{*}{$\beta_{6}$} & $0.0043^{*}$ & $0.0191^{* * *}$ & $0.0046^{* * *}$ & $0.0145^{* * *}$ \\
\hline & $(0.0022)$ & $(0.0038)$ & $(0.0017)$ & $(0.0037)$ \\
\hline \multirow[t]{2}{*}{$\beta_{7}$} & 0.0028 & $0.0163^{* * *}$ & $0.0039^{* *}$ & $0.0124^{* * *}$ \\
\hline & $(0.0023)$ & $(0.0043)$ & $(0.0015)$ & $(0.0041)$ \\
\hline \multirow[t]{2}{*}{$\beta_{8}$} & 0.0018 & $0.0204^{* * *}$ & $0.0043^{* *}$ & $0.0162^{* * *}$ \\
\hline & $(0.0024)$ & $(0.0036)$ & $(0.0017)$ & $(0.0036)$ \\
\hline \multirow[t]{2}{*}{$\beta_{9}$} & 0.0006 & $0.0211^{* * *}$ & $0.0049^{* *}$ & $0.0161^{* * *}$ \\
\hline & $(0.0032)$ & $(0.0058)$ & $(0.0019)$ & $(0.0055)$ \\
\hline \multirow[t]{2}{*}{$\phi$} & $-0.0091^{* * *}$ & $-0.0161^{* * *}$ & -0.0005 & $-0.0156^{* * *}$ \\
\hline & $(0.0005)$ & $(0.0018)$ & $(0.0005)$ & $(0.0018)$ \\
\hline$N$ & 349680 & 349680 & 349680 & 349680 \\
\hline$R^{2}$ & 0.271 & 0.006 & 0.001 & 0.006 \\
\hline
\end{tabular}

Note: Robust standard errors in parentheses are clustered by region of entry per year of entry. significant at $1 \%, * *$ significant at $5 \%$, significant at $10 \%$. Regressions include dummies for year of entry, region of entry, region of birth and current year. We control also for initial firm (sector, average number of employees, age) and type of occupation. See equation 1 for the interpretation of $\phi, \beta$ and $\psi$ coefficients. 
Table A10: The effect of initial and contemporaneous labor market conditions on weekly wage and individual level injuries: Allowing different dynamics for stayers in the entry firm and movers

\begin{tabular}{|c|c|c|c|c|}
\hline & (1) & (2) & (3) & (4) \\
\hline & ln(wage) & All injuries & IC injuries & NIC injuries \\
\hline \multirow[t]{2}{*}{$\psi_{1}$} & $0.1162^{* * *}$ & $-0.0873^{* * *}$ & $-0.0205^{*}$ & $-0.0667^{* *}$ \\
\hline & $(0.0090)$ & $(0.0299)$ & $(0.0106)$ & $(0.0275)$ \\
\hline \multirow[t]{2}{*}{$\psi_{2}$} & $0.2592^{* * *}$ & $-0.1198^{* * *}$ & $-0.0243^{* *}$ & $-0.0955^{* * *}$ \\
\hline & $(0.0154)$ & $(0.0336)$ & $(0.0118)$ & $(0.0312)$ \\
\hline \multirow[t]{2}{*}{$\psi_{3}$} & $0.3799^{* * *}$ & $-0.1788^{* * *}$ & $-0.0424^{* * *}$ & $-0.1364^{* * *}$ \\
\hline & $(0.0202)$ & $(0.0381)$ & $(0.0125)$ & $(0.0341)$ \\
\hline \multirow[t]{2}{*}{$\psi_{4}$} & $0.4794^{* * *}$ & $-0.2288^{* * *}$ & $-0.0658^{* * *}$ & $-0.1630^{* * *}$ \\
\hline & $(0.0251)$ & $(0.0469)$ & $(0.0171)$ & $(0.0437)$ \\
\hline \multirow[t]{2}{*}{$\psi_{5}$} & $0.5332^{* * *}$ & $-0.2299^{* * *}$ & $-0.0431^{* *}$ & $-0.1869^{* * *}$ \\
\hline & $(0.0323)$ & $(0.0554)$ & $(0.0180)$ & $(0.0492)$ \\
\hline \multirow[t]{2}{*}{$\psi_{6}$} & $0.6214^{* * *}$ & $-0.3158^{* * *}$ & $-0.0800^{* * *}$ & $-0.2359^{* * *}$ \\
\hline & $(0.0421)$ & $(0.0682)$ & $(0.0208)$ & (0.0597) \\
\hline \multirow[t]{2}{*}{$\psi_{7}$} & $0.6424^{* * *}$ & $-0.2510^{* * *}$ & $-0.0534^{* *}$ & $-0.1975^{* * *}$ \\
\hline & $(0.0420)$ & $(0.0776)$ & $(0.0206)$ & $(0.0730)$ \\
\hline \multirow[t]{2}{*}{$\psi_{8}$} & $0.6898^{* * *}$ & $-0.3063^{* * *}$ & $-0.0818^{* * *}$ & $-0.2245^{* * *}$ \\
\hline & $(0.0500)$ & $(0.0917)$ & $(0.0263)$ & $(0.0794)$ \\
\hline \multirow[t]{2}{*}{$\psi_{9}$} & $0.7213^{* * *}$ & $-0.3113^{* * *}$ & $-0.0566^{*}$ & $-0.2547^{* *}$ \\
\hline & $(0.0621)$ & $(0.1108)$ & $(0.0311)$ & $(0.1008)$ \\
\hline \multirow[t]{2}{*}{$\psi_{1, n f e}$} & $-0.0337^{* * *}$ & $0.1085^{* * *}$ & -0.0009 & $0.1095^{* * *}$ \\
\hline & $(0.0104)$ & $(0.0341)$ & $(0.0069)$ & $(0.0337)$ \\
\hline \multirow[t]{2}{*}{$\psi_{2, n f e}$} & $-0.0694^{* * *}$ & $0.0856^{* * *}$ & $0.0120^{*}$ & $0.0736^{* *}$ \\
\hline & $(0.0099)$ & $(0.0299)$ & $(0.0062)$ & $(0.0290)$ \\
\hline \multirow[t]{2}{*}{$\psi_{3, n f e}$} & $-0.0984^{* * *}$ & $0.1055^{* * *}$ & $0.0290^{* * *}$ & $0.0766^{* * *}$ \\
\hline & $(0.0110)$ & $(0.0276)$ & $(0.0086)$ & $(0.0262)$ \\
\hline \multirow{2}{*}{$\psi_{4, n f e}$} & $-0.1156^{* * *}$ & $0.0946^{* * *}$ & $0.0228^{* *}$ & $0.0718^{* *}$ \\
\hline & $(0.0114)$ & $(0.0267)$ & $(0.0088)$ & $(0.0278)$ \\
\hline \multirow[t]{2}{*}{$\psi_{5, n f e}$} & $-0.0989^{* * *}$ & $0.0831^{* * *}$ & -0.0074 & $0.0905^{* * *}$ \\
\hline & $(0.0118)$ & $(0.0270)$ & $(0.0071)$ & $(0.0267)$ \\
\hline \multirow[t]{2}{*}{$\psi_{6, n f e}$} & $-0.1232^{* * *}$ & $0.1666^{* * *}$ & $0.0235^{* *}$ & $0.1431^{* * *}$ \\
\hline & $(0.0178)$ & $(0.0279)$ & $(0.0099)$ & $(0.0281)$ \\
\hline \multirow[t]{2}{*}{$\psi_{7, n f e}$} & $-0.0837^{* * *}$ & $0.0866^{* *}$ & -0.0125 & $0.0992^{* * *}$ \\
\hline & $(0.0128)$ & $(0.0335)$ & $(0.0123)$ & $(0.0327)$ \\
\hline \multirow[t]{2}{*}{$\psi_{8, n f e}$} & $-0.0795^{* * *}$ & 0.0991 & 0.0133 & 0.0858 \\
\hline & $(0.0175)$ & $(0.0619)$ & $(0.0105)$ & $(0.0621)$ \\
\hline \multirow[t]{2}{*}{$\psi_{9, n f e}$} & $-0.0582^{* *}$ & $0.1015^{* *}$ & -0.0298 & $0.1313^{* *}$ \\
\hline & $(0.0291)$ & $(0.0510)$ & $(0.0230)$ & $(0.0515)$ \\
\hline
\end{tabular}

Continues on the next page 
Table A10 continued

\begin{tabular}{|c|c|c|c|c|}
\hline & (1) & (2) & (3) & (4) \\
\hline & $\ln$ (wage) & All injuries & IC injuries & NIC injuries \\
\hline \multirow[t]{2}{*}{$\beta_{0}$} & $0.0156^{* * *}$ & $0.0111^{* * *}$ & $0.0047^{* * *}$ & $0.0064^{*}$ \\
\hline & $(0.0018)$ & $(0.0032)$ & $(0.0016)$ & $(0.0034)$ \\
\hline \multirow[t]{2}{*}{$\beta_{1}$} & $0.0137^{* * *}$ & $0.0135^{* * *}$ & $0.0046^{* * *}$ & $0.0089^{* * *}$ \\
\hline & $(0.0018)$ & $(0.0029)$ & $(0.0015)$ & $(0.0034)$ \\
\hline \multirow[t]{2}{*}{$\beta_{2}$} & $0.0115^{* * *}$ & $0.0138^{* * *}$ & $0.0039^{* * *}$ & $0.0099^{* * *}$ \\
\hline & $(0.0019)$ & $(0.0029)$ & $(0.0014)$ & $(0.0031)$ \\
\hline \multirow[t]{2}{*}{$\beta_{3}$} & $0.0102^{* * *}$ & $0.0169^{* * *}$ & $0.0048^{* * *}$ & $0.0121^{* * *}$ \\
\hline & $(0.0021)$ & $(0.0032)$ & $(0.0014)$ & $(0.0034)$ \\
\hline \multirow[t]{2}{*}{$\beta_{4}$} & $0.0069^{* * *}$ & $0.0198^{* * *}$ & $0.0063^{* * *}$ & $0.0135^{* * *}$ \\
\hline & $(0.0022)$ & $(0.0033)$ & $(0.0016)$ & $(0.0038)$ \\
\hline \multirow[t]{2}{*}{$\beta_{5}$} & $0.0077^{* * *}$ & $0.0197^{* * *}$ & $0.0035^{* *}$ & $0.0162^{* * *}$ \\
\hline & $(0.0024)$ & $(0.0033)$ & $(0.0015)$ & $(0.0036)$ \\
\hline \multirow[t]{2}{*}{$\beta_{6}$} & 0.0033 & $0.0295^{* * *}$ & $0.0062^{* * *}$ & $0.0233^{* * *}$ \\
\hline & $(0.0034)$ & $(0.0045)$ & $(0.0017)$ & $(0.0043)$ \\
\hline \multirow[t]{2}{*}{$\beta_{7}$} & $0.0056^{*}$ & $0.0196^{* * *}$ & $0.0034^{* *}$ & $0.0162^{* * *}$ \\
\hline & $(0.0031)$ & $(0.0053)$ & $(0.0016)$ & $(0.0054)$ \\
\hline \multirow[t]{2}{*}{$\beta_{8}$} & 0.0052 & $0.0286^{* * *}$ & $0.0046^{* * *}$ & $0.0240^{* * *}$ \\
\hline & $(0.0037)$ & $(0.0059)$ & $(0.0016)$ & $(0.0063)$ \\
\hline \multirow[t]{2}{*}{$\beta_{9}$} & 0.0044 & $0.0245^{* *}$ & 0.0022 & $0.0224^{* *}$ \\
\hline & $(0.0058)$ & $(0.0104)$ & $(0.0026)$ & $(0.0101)$ \\
\hline \multirow[t]{2}{*}{$\beta_{1, n f e}$} & $0.0023^{* *}$ & -0.0028 & 0.0004 & -0.0032 \\
\hline & $(0.0010)$ & $(0.0030)$ & $(0.0008)$ & $(0.0029)$ \\
\hline \multirow[t]{2}{*}{$\beta_{2, n f e}$} & $0.0026^{* * *}$ & -0.0030 & -0.0007 & -0.0023 \\
\hline & $(0.0008)$ & $(0.0022)$ & $(0.0005)$ & $(0.0021)$ \\
\hline \multirow[t]{2}{*}{$\beta_{3, n f e}$} & 0.0015 & -0.0021 & $-0.0020^{* * *}$ & -0.0001 \\
\hline & $(0.0010)$ & $(0.0023)$ & $(0.0006)$ & $(0.0022)$ \\
\hline \multirow[t]{2}{*}{$\beta_{4, n f e}$} & $0.0034^{* * *}$ & -0.0016 & $-0.0019^{*}$ & 0.0003 \\
\hline & $(0.0010)$ & $(0.0024)$ & $(0.0010)$ & $(0.0027)$ \\
\hline \multirow[t]{2}{*}{$\beta_{5, n f e}$} & 0.0007 & 0.0017 & $0.0011^{*}$ & 0.0006 \\
\hline & $(0.0013)$ & $(0.0029)$ & $(0.0006)$ & $(0.0028)$ \\
\hline \multirow[t]{2}{*}{$\beta_{6, n f e}$} & 0.0031 & $-0.0083^{* * *}$ & -0.0016 & $-0.0067^{* *}$ \\
\hline & $(0.0021)$ & $(0.0030)$ & $(0.0011)$ & $(0.0028)$ \\
\hline \multirow[t]{2}{*}{$\beta_{7, n f e}$} & -0.0011 & -0.0006 & 0.0009 & -0.0014 \\
\hline & $(0.0015)$ & $(0.0036)$ & $(0.0010)$ & $(0.0034)$ \\
\hline \multirow[t]{2}{*}{$\beta_{8, n f e}$} & -0.0016 & -0.0061 & -0.0002 & -0.0059 \\
\hline & $(0.0021)$ & $(0.0068)$ & $(0.0008)$ & $(0.0068)$ \\
\hline \multirow[t]{2}{*}{$\beta_{9, n f e}$} & -0.0020 & -0.0007 & $0.0033^{*}$ & -0.0040 \\
\hline & $(0.0036)$ & $(0.0067)$ & $(0.0018)$ & $(0.0065)$ \\
\hline \multirow[t]{2}{*}{$\phi$} & $-0.0078^{* * *}$ & $-0.0166^{* * *}$ & -0.0007 & $-0.0159^{* * *}$ \\
\hline & $(0.0005)$ & $(0.0018)$ & $(0.0004)$ & $(0.0017)$ \\
\hline$N$ & 362682 & 362682 & 362682 & 362682 \\
\hline$R^{2}$ & 0.167 & 0.003 & 0.000 & 0.003 \\
\hline
\end{tabular}

Note: Robust standard errors in parentheses are clustered by region of entry $\mathrm{x}$ year of entry. $* * *$ significant at $1 \%,{ }^{* *}$ significant at $5 \%,{ }^{*}$ significant at $10 \%$. Regressions include dummies for year of entry, region of entry, region of birth and current year. $\beta_{s}$ coefficients represent the effect of unemployment at entry in year $s$. $\beta_{s, n f e}$ coefficients represent the effect of unemployment at entry in year $s$ in a firm different from the first employer. See equation 1 for the interpretation of $\phi$ and $\psi$ coefficients. 